\title{
Photochemical Nitration by Tetranitromethane. Part XXXIII.† Adduct Formation in the Photochemical Reactions of 1,2,4,5- and 1,2,3,5-Tetramethylbenzene
}

\author{
Craig P. Butts, ${ }^{a}$ Lennart Eberson, ${ }^{b},{ }^{*}$ Karen L. Fulton, ${ }^{a}$ Michael P. Hartshorn, ${ }^{a},{ }^{*}$ \\ Ward T. Robinson, ${ }^{a}$ and David J. Timmerman-Vaughan ${ }^{a}$
}

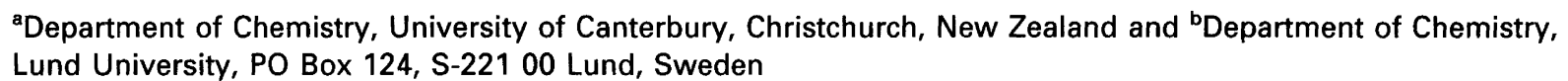

\begin{abstract}
Butts, C. P., Eberson, L., Fulton, K. L., Hartshorn, M. P., Robinson, W. T. and Timmerman-Vaughan, D. J., 1996. Photochemical Nitration by Tetranitromethane. Part XXXIII. Adduct Formation in the Photochemical Reactions of 1,2,4,5- and 1,2,3,5-Tetramethylbenzene. - Acta Chem. Scand. 50: 991-1008. (C) Acta Chemica Scandinavica 1996.

The photolysis of the charge-transfer complex of tetranitromethane and $1,2,4,5$-tetramethylbenzene in dichloromethane or acetonitrile gives the epimeric 1,3,4,6-tetramethyl-3-nitro-6-trinitromethylcyclohexa-1,4-dienes 8 and 9, in addition to products of nuclear nitration 12 and side-chain modification 10, 11, and 13-18. Similar reactions of 1,2,3,5-tetramethylbenzene gave trans-1,3,5,6-tetramethyl-6-nitro-3-trinitromethylcyclohexa-1,4-diene 30 and two isomeric 'double' adducts $\mathbf{3 1}$ and 32, in addition to products of nuclear nitration 27 and side-chain modification 26,28 and 29. The eliminative rearrangements of adducts 8 and 30 to give re-aromatized products in acetonitrile or $\left[{ }^{2} \mathrm{H}_{3}\right]$ acetonitrile and in $\left[{ }^{2} \mathrm{H}\right]$ chloroform are reported. The photolysis of the charge-transfer complexes of tetranitromethane with either 1,2,4,5-tetramethylbenzene or 1,2,3,5-tetramethylbenzene in 1,1,1,3,3,3-hexafluoropropan-2-ol (HFP) gives a marked increase in the yields of ring-nitration products 12 or 27 , respectively, reactions presumed to proceed via a nitrosation-oxidation sequence. Reaction of 1,2,4,5-tetramethylbenzene with excess nitrogen dioxide in HFP also results in extensive ring nitration to give 12 and 2,3,5,6-tetramethyl-1,4-dinitrobenzene (25); the latter compound is seen as arising via the 2,3,5,6-tetramethyl-1,4-dinitrosobenzene (34). Similar reaction of 1,2,3,5-tetramethylbenzene gives ring-nitration product 27 as the major product. X-Ray crystal structures are reported for 2,4,6-trimethyl-1-(2',2',2'-trinitroethyl)benzene (26) and trans1,3,5,6-tetramethyl-6-nitro-3-trinitromethyl-cyclohexa-1,4-diene (30).
\end{abstract}

The photochemical addition of tetranitromethane (TNM) to aromatic compounds (ArH) by excitation of the ArH-TNM charge-transfer (CT) complex by light matching the wavelength of the CT band has been shown ${ }^{2}$ to occur by recombination of a triad consisting of $\mathrm{ArH}^{\circ}$, trinitromethanide ion, and nitrogen dioxide.

$$
\begin{aligned}
& \mathrm{ArH}^{\cdots} \mathrm{C}\left(\mathrm{NO}_{2}\right)_{4} \rightarrow \mathrm{ArH}^{+}\left(\mathrm{O}_{2} \mathrm{~N}\right)_{3} \mathrm{C}^{-} \mathrm{NO}_{2} \\
& \text { CT complex } \\
& \text { triad }
\end{aligned}
$$

The first chemical step which occurs, leading to the formation of adducts, is reaction between $\mathrm{ArH}^{+}$and trinitromethanide ion [eqn. (2)] to give a carbon radical which then reacts with nitrogen dioxide to give adducts [eqn. (3)]. ${ }^{2}$

$$
\mathrm{ArH}^{+}+\left(\mathrm{O}_{2} \mathrm{~N}\right)_{3} \mathrm{C}^{-} \rightarrow \operatorname{Ar}(\mathrm{H}) \mathrm{C}\left(\mathrm{NO}_{2}\right)_{3}{ }^{\circ}
$$

\footnotetext{
$\dagger$ Part XXXII, see Ref. 1.

* To whom correspondence should be addressed.
}

$$
\operatorname{Ar}(\mathrm{H}) \mathrm{C}\left(\mathrm{NO}_{2}\right)_{3}{ }^{\circ}+\mathrm{NO}_{2} \rightarrow \text { adducts }
$$

Although no adducts were reported to be formed in the photochemical reactions of 1,3,5-trimethylbenzene (1), 1,2,4,5-tetramethylbenzene (2), pentamethylbenzene (3), or hexamethylbenzene (4) with tetranitromethane, ${ }^{3}$ adducts and products of their secondary reactions were identified in the analogous reactions of benzene, ${ }^{4}$ 1,2,3-trimethylbenzene (5), ${ }^{5}$ and in 1,2,3,4-tetramethylbenzene (6). ${ }^{6}$

We now report the results of a re-examination of the photochemical reactions of 1,2,4,5-tetramethylbenzene (2) (durene) with tetranitromethane, and the corresponding reactions of 1,2,3,5-tetramethylbenzene (7) (isodurene). Such reaction of 1,2,4,5-tetramethylbenzene at $-50{ }^{\circ} \mathrm{C}$ in dichloromethane for $4 \mathrm{~h}$ gave two unstable adducts (total absolute yield 38\%), while 1,2,3,5-tetramethylbenzene under the same conditions showed a somewhat lower conversion into adducts (30\%). 
<smiles>Cc1cc(C)cc(C)c1</smiles><smiles>Cc1cc(C)c(C)cc1C</smiles><smiles>Cc1cc([N+](=O)[O-])c([N+](=O)[O-])c([N+](=O)[O-])c1</smiles><smiles>Cc1c(C)c(C)c(C)c(C)c1C</smiles><smiles>Cc1cccc(C)c1[N+](=O)[O-]</smiles>

5<smiles>Cc1ccc([N+](=O)[O-])c([N+](=O)[O-])c1[N+](=O)[O-]</smiles>

6<smiles>O=[N+]c1cc([N+](=O)[O-])cc([N+](=O)[O-])c1</smiles>

\section{Results}

General. The photochemical experiments were performed with filtered light (cut-off $435 \mathrm{~nm}, 5 \mathrm{~cm}$ water IR-filter, from a $300 \mathrm{~W}$ incandescent lamp) as described before, ${ }^{7}$ and small samples were withdrawn for analysis at suitable intervals. The work-up procedure, involving evaporation of solvent and excess tetranitromethane, was conducted at a temperature $\leqslant 0^{\circ} \mathrm{C}$. The crude product mixtures were stored at $-78^{\circ} \mathrm{C}$ and were analysed $\left({ }^{1} \mathrm{H}\right.$ NMR spectroscopy, see Experimental section; Tables 1-4, 8, and 9) as soon as possible.

Photochemistry of 1,2,4,5-tetramethylbenzene (2) in dichloromethane at $-50^{\circ} \mathrm{C}$ and the identification of adducts 8 and 9. A solution of $2\left(0.47 \mathrm{~mol} \mathrm{dm}^{-3}\right)$ and tetranitromethane $\left(0.94 \mathrm{~mol} \mathrm{dm}{ }^{-3}\right)$ in dichloromethane was irradiated at $-50^{\circ} \mathrm{C}$. The composition of the mixture was monitored by NMR spectral analysis (Table 1 ). The final solution (after $4 \mathrm{~h}$, conversion $71 \%$ ) contained the epimeric 1,3,4,6-tetramethyl-3-nitro-6-trinitromethylcyclohexa-1,4-dienes $8(46 \%)$ and $9(7 \%)$, aromatic com- pounds 10-17 (total 41\%) and unidentified aromatic compounds (total 6\%). The adducts 8 and 9 were separated partially by HPLC on a cyanopropyl column using hexane-dichloromethane mixtures as the eluting solvents. The first material eluted was a mixture of aromatic compounds, the separation and identification of which is given below.

Adducts 8 and 9 were assigned the epimeric 1,3,4,6-tetramethyl-3-nitro-6-trinitromethylcyclohexa-1, 4diene structures from of a consideration of their spectroscopic data (Experimental section). The connectivity of each of adducts 8 and 9 was established from the results of nuclear Overhauser experiments and longrange reverse-detected heteronuclear correlation spectra (HMBC, HMQC). The ${ }^{1} \mathrm{H}$ and ${ }^{13} \mathrm{C}$ NMR spectra for adducts 8 and 9 , so assigned, were closely similar as expected for epimeric compounds. Of particular relevance were the ${ }^{13} \mathrm{C}$ NMR resonances for $\mathrm{C} 3$ and $\mathrm{C} 6$ for $8(\delta$ 88.3 and 51.2$)$ and $9(\delta 85.4$ and 50.6$)$, which indicated the attachment of nitro and trinitromethyl groups, respectively, at those ring positions. The relative stereo-<smiles>CC1=C[C@@](C(=O)O[Na])([N+](=O)[O-])C(C)=C[C@]1(C)O</smiles>

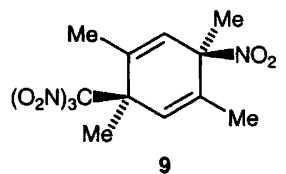<smiles>Cc1cc(C)c(C=O)cc1C</smiles>
14<smiles>Cc1cc(C)c(C[N+](=O)[O-])cc1C</smiles>

13<smiles>Cc1cc(Cc2c(C)c([N+](=O)[O-])cc(C)c2[N+](=O)[O-])c([N+](=O)[O-])cc1[N+](=O)[O-]</smiles><smiles>Cc1cc(C)c(CO)cc1C</smiles>

15<smiles>Cc1cc(C)c(CC(=O)O[Na])cc1C</smiles>

11<smiles>COOCc1cc(C)c(C)cc1C</smiles>

16<smiles>Cc1cc(C)c([N+](=O)[O-])c([N+](=O)[O-])c1C</smiles>

12<smiles>CC(=O)N(Cc1cc([N+](=O)[O-])c([N+](=O)[O-])cc1C)C(C)=O</smiles>

19<smiles>CC(=O)NCc1c(C)c([N+](=O)[O-])c([N+](=O)[O-])c([N+](=O)[O-])c1C</smiles>

20<smiles>CC(=O)N(Cc1c(C)c(C)c([N+](=O)[O-])c([N+](=O)[O-])c1C)C(C)=O</smiles>

21<smiles>Cc1cc(C)c(COO)cc1C</smiles>

17 

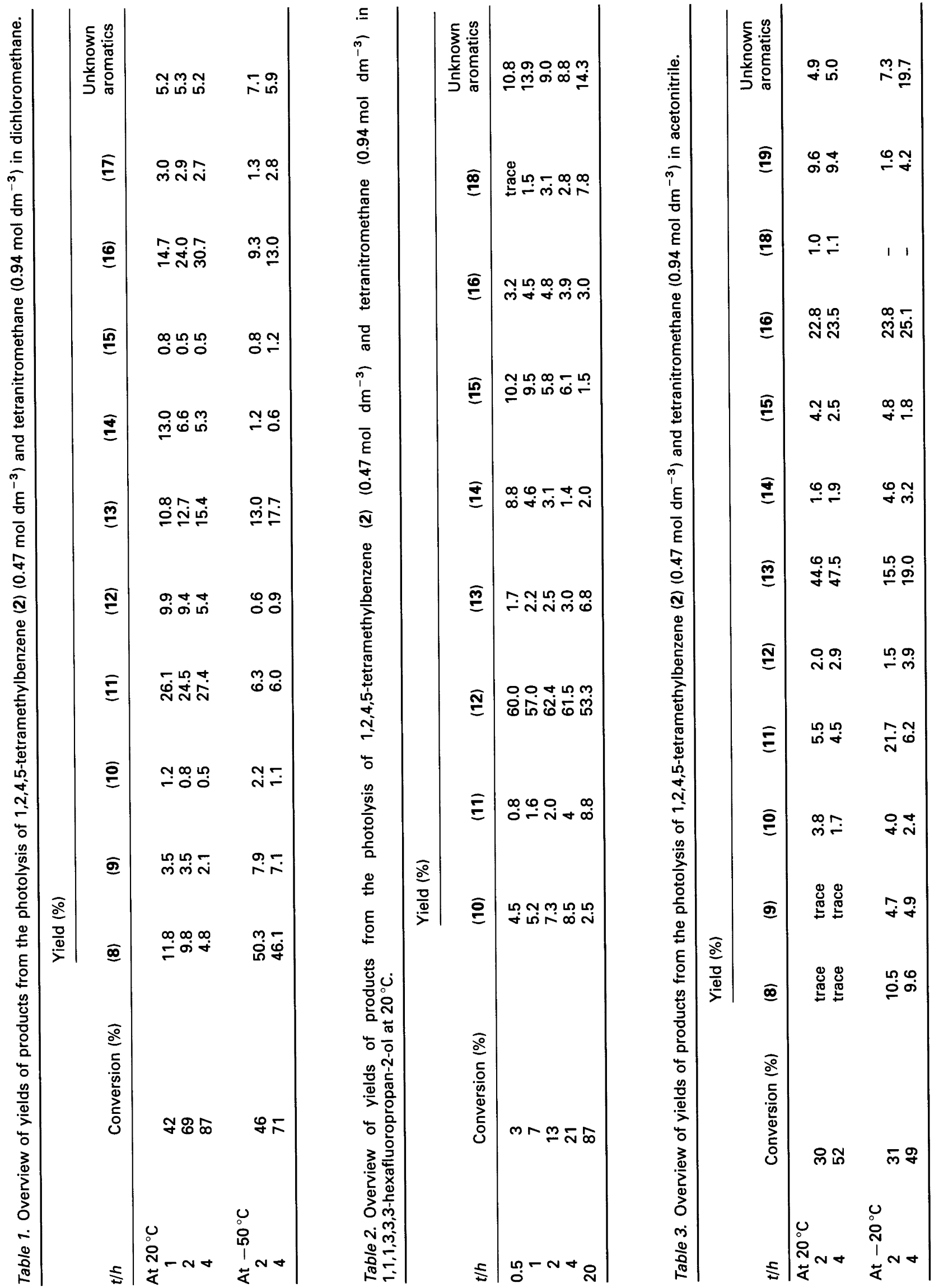
chemistry of 8 and 9 was assigned on the basis of their elution order from a cyanopropyl HPLC column with the dichloromethane-hexane solvent system, trans1-trinitromethyl-4-nitro adducts being less polar than their cis-isomers. ${ }^{5,7}$ Adduct 9 was obtained only in admixture with $\mathbf{8}$, but its spectroscopic data were obtained by subtraction of the known spectra for adduct 8 . The connectivity of each of adducts 8 and 9 was established from the results of nuclear Overhauser experiments and long-range reverse-detected heteronuclear correlation spectra (HMBC, HMQC). Although confirmation of the molecular formula of $\mathbf{8}$ was not possible by either elemental analysis or by mass spectrometry, due to its instability, the structures assigned to adducts 8 and 9 appear secure.

Photochemistry of 1,2,4,5,-tetramethylbenzene (2) in 1,1,1,3,3,3-hexafluoropropan-2-ol (HFP) at $20^{\circ} \mathrm{C}$ and the identification of the aromatic products 10-15 and 18. Photolysis of the CT complex of 2-tetranitromethane in HFP at $20^{\circ} \mathrm{C}$, as above, gave a mixture of the aromatic compounds 10-16 and 18 (Table 2). The degree of conversion was $87 \%$ after $20 \mathrm{~h}$. Chromatography of this mixture on a silica gel Chromatotron plate allowed the separation of compounds 10-15 and 18, with the benzylic nitrate 16 being presumably hydrolysed during the chromatography to give further benzylic alcohol 15. Of the products isolated, compounds 10 and 12-15 were identified by comparison with authentic material (Experimental section). Compounds 11 and 18 were isolated only in small quantities, but their respective molecular formulae were established from mass spectra and their structures from a consideration of their spectroscopic data. For each of 11 and 18, the connectivity in the structures was established by a combination of the results of nuclear Overhauser experiments, and longrange reverse-detected heteronuclear correlation spectra (HMBC, HMQC). The presence of 2,4,5-trimethylbenzyl nitrate (16) in the reaction mixture was inferred from the ${ }^{1} \mathrm{H}$ NMR spectroscopic signal due to the $-\mathbf{C H}_{2}-$ $\mathrm{ONO}_{2}$ group. $^{3}$

Photochemistry of 1,2,4,5-tetramethylbenzene (2) in acetonitrile at $20^{\circ} \mathrm{C}$ and the identification of the $\mathrm{N}$-nitrosoacetamide (19). Photolysis of the CT complex of 2-tetranitromethane in acetonitrile at $20^{\circ} \mathrm{C}$, as above, gave $52 \%$ conversion after $4 \mathrm{~h}$ into a mixture of the aromatic compounds $10-16$ and 18 (total $86 \%$ ), the $N$ nitrosoacetamide $19(9 \%)$ and unidentified aromatic products $(5 \%)$ (Table 3 ). Chromatography of this mixture on a silica gel Chromatotron plate gave a small amount of 19 in a fraction eluted immediately before the aldehyde 14. The molecular formula, $\mathrm{C}_{12} \mathrm{H}_{16} \mathrm{~N}_{2} \mathrm{O}_{2}$, of 19 was obtained from its mass spectrum, and the attachment of three methyl groups and a methylene function to the aromatic ring was indicated by the results of nuclear Overhauser experiments. The remainder of the structure of 19 was assigned by analogy with the spectroscopic data for pentamethylbenzylacetamide (20) and its $\mathrm{N}$ nitroso derivative $21 .{ }^{8}$ Comparative IR, ${ }^{1} \mathrm{H}$ and ${ }^{13} \mathrm{C}$ NMR spectroscopic data are presented in Fig. 1 for the two $N$-nitroso compounds 19 and $21,{ }^{8}$ and the parent compound 20 of the latter. It should be emphasized that only small quantities of the two $\mathrm{N}$-nitroso compounds 19 and $21^{8}$ could be isolated by rapid chromatography on silica gel Chromatotron plates of mixtures containing significant quantities of each compound. In particular, the $N$-nitrosoacetamide structure 19 is in accord with the carbonyl stretching frequency $\left(1726 \mathrm{~cm}^{-1}\right)$, reflecting the effect of the electron-withdrawing $N$-nitroso group. ${ }^{9}$ Further, the ${ }^{13} \mathrm{C}$ NMR resonances $\delta 174.6$ (amide carbonyl carbon), $\delta 22.8\left(\mathrm{CH}_{3}-\mathrm{CO}-\right)$ and $\delta 39.5\left(\mathbf{C H}_{2}\right)$ are consistent with the $N$-(2,4,5-trimethylbenzyl)- $N$-nitrosoacetamide structure. Finally, 19 would be expected to suffer a ready loss of a fragment of mass 30 (NO) in the mass spectrum, as is observed. The above assignments were confirmed by long-range reverse-detected heteronuclear correlation spectra (HMBC, HMQC).

Photochemistry of 1,2,4,5-tetramethylbenzene (2) in dichloromethane at $20^{\circ} \mathrm{C}$. Photolysis of the CT complex of 2-tetranitromethane in dichloromethane for $4 \mathrm{~h}$ at $20^{\circ} \mathrm{C}$, as above, gave mixtures of products, the composition of which are summarized in Table 1.

Photochemistry of 1,2,4,5-tetramethylbenzene (2) in dichloromethane containing trifluoroacetic acid $(0.7 \mathrm{M})$ at $20^{\circ} \mathrm{C}$. Photolysis of the $\mathrm{CT}$ complex of 2-tetranitromethane, as above, in dichloromethane containing trifluoroacetic acid $(0.7 \mathrm{M})$ gave a mixture of the aromatic compounds 10-14, 16 and 18, and unidentified aromatic products $(20 \%)$ (Table 4$)$. Notable among these products is the side-chain trinitromethyl derivative 11, formed in $3 \%$ absolute yield after $4 \mathrm{~h}$.

Eliminative rearrangement of 1,3,4,6-tetramethyl-r-3nitro-t-6-trinitromethylcyclohexa-1,4-diene (8) in acetonitrile at $20^{\circ} \mathrm{C}$. A solution of $\mathbf{8}$ in acetonitrile was stored in the dark at $20^{\circ} \mathrm{C}$; aliquots were removed at appropriate time intervals and the solvent was removed at $\leqslant 0{ }^{\circ} \mathrm{C}$ to give residues, the composition of which was determined by ${ }^{1} \mathrm{H}$ NMR spectral analysis. Initially (within $5 \mathrm{~min}$ ) adduct 8 underwent epimerization to give adduct 9, and also nitro-nitrito rearrangement to give the epimeric trinitromethyl nitrite esters 22a and 23a. During the workup procedure 22a and 23a were hydrolysed to give the corresponding trinitromethyl alcohols 22b and 23b, the ${ }^{1} \mathrm{H}$ NMR spectra of which are given in the Experimental section. Subsequently (over ca. $1 \mathrm{~h}$ ) the equilibrium mixture of $8,9,22 \mathrm{a}$ and 23a was converted into a mixture of $11(14 \%), 12(18 \%), 13(11 \%), 15(7 \%)$, $16(3 \%)$ and unidentified aromatic products (total $33 \%$ ).

Eliminative rearrangement of 1,3,4,6-tetramethyl-r-3-nitro$\mathrm{t}$-6-trinitromethylcyclohexa-1,4-diene $(\mathbf{8})$ in $\left[{ }^{2} \mathrm{H}\right]$ chloroform at $20^{\circ} \mathrm{C}$. A solution of 8 in $\left[{ }^{2} \mathrm{H}\right]$ chloroform was 


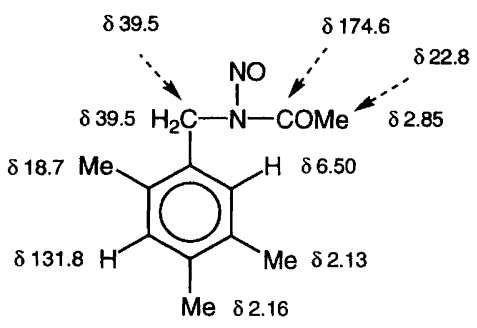

$19\left(v_{\max } 1726,1499,1128 \mathrm{~cm}^{-1}\right)$

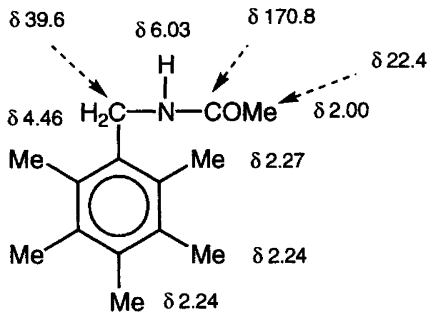

$20\left(v_{\max } 3304,1643,1537,1385 \mathrm{~cm}^{-1}\right)$

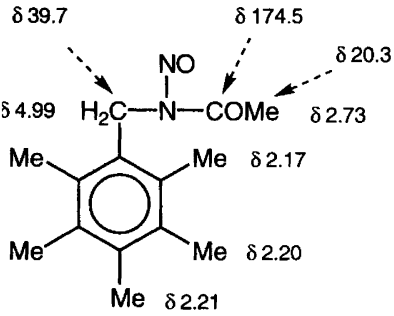

$21\left(v_{\max } 1719,1504,1121 \mathrm{~cm}^{-1}\right)$

Fig. 1. IR, ${ }^{1} \mathrm{H}$ and ${ }^{13} \mathrm{C}$ NMR data for compounds $19-21$.
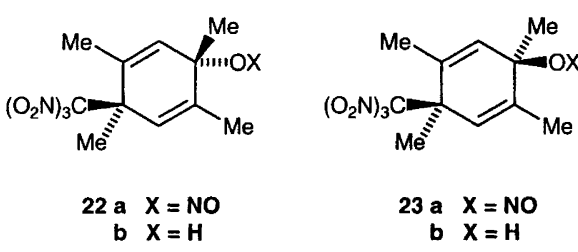

stored in the dark at $20^{\circ} \mathrm{C}$ and the ${ }^{1} \mathrm{H}$ NMR spectrum of the solution monitored at appropriate time intervals. In this solvent 8 epimerized only slowly, equilibrium with its epimer 9 being established after $90 \mathrm{~h}$. The trinitromethyl nitrite esters 22a and 23a were not observed in this rearrangement, 8 and 9 being slowly converted ( 25 days) into a mixture of $11(52 \%), 13(18 \%), 14(6 \%), 16(10 \%)$ and some unidentified aromatic compounds (total 13\%).

Reaction of 1,2,4,5-tetramethylbenzene (2) with nitrogen dioxide in dichloromethane at $20^{\circ} \mathrm{C}$. A solution of 2 in dichloromethane saturated with nitrogen dioxide was irradiated with filtered light $\left(\lambda_{\text {cut-off }} 435 \mathrm{~nm}\right)$ at $20^{\circ} \mathrm{C}$. A similar mixture was stored in the dark at $20^{\circ} \mathrm{C}$. Aliquots were removed at appropriate time intervals and the excess nitrogen dioxide and solvent were removed under reduced pressure at $\leqslant 0^{\circ} \mathrm{C}$. The product compositions were determined by ${ }^{1} \mathrm{H}$ NMR spectral analysis and are given in Table 5. After reaction for $4 \mathrm{~h}$ the two product compositions were similar, viz. 2,4,5-trimethylbenzyl nitrate 16 (ca. 70\%), 2,4,5-trimethylphenylnitromethane 13 (ca. 20\%), with small amounts of aromatic compounds 10, 14 and 15, and unidentified compounds. These results are comparable with those reported recently by Bosch and Kochi, ${ }^{10}$ except that they also observed a low yield of the nuclear nitration product 12.

Reaction of 1,2,4,5-tetramethylbenzene (2) with nitrogen dioxide in 1,1,1,3,3,3-hexafluoropropan-2-ol (HFP) at $20^{\circ} \mathrm{C}$. A solution of 2 in HFP saturated with nitrogen dioxide was irradiated with filtered light ( $\lambda_{\text {cut-off }} 435 \mathrm{~nm}$ ) at $20^{\circ} \mathrm{C}$. A similar mixture was stored in the dark at $20^{\circ} \mathrm{C}$. After $0.5 \mathrm{~h}$, at which time all of 2 in both reactions had been consumed, the excess nitrogen dioxide and solvent were removed under reduced pressure at $\leqslant 0{ }^{\circ} \mathrm{C}$. The product compositions, determined by ${ }^{1} \mathrm{H}$ NMR spectral analysis, were similar, viz. 12 (ca. 72\%), 24 (ca.
$16 \%$ ) and 25 (ca. 4\%) with small amounts of aromatic compounds 13 and 14, and unidentified compounds.

EPR spectroscopic studies of the photochemical reaction between 1,2,4,5-tetramethylbenzene (2) and tetranitromethane. We have previously shown ${ }^{11}$ that radical cations that are not too reactive can be observed by EPR spectroscopy in irradiated solutions of ArH-tetranitromethane-trifluoroacetic acid $\left(0.8 \mathrm{~mol} \mathrm{\textrm {dm } ^ { - 3 } )}\right.$ in dichloromethane at low temperature (usually -60 to $-70^{\circ} \mathrm{C}$ ); without acid present the spectrum was either much weaker or not observable at all. This behaviour was interpreted as being caused by protonation of trinitromethanide ion, which thus is removed from the triad and replaced by the much weaker nucleophile, nitroform.

Application of this method to 1,2,4,5-tetramethylbenzene 2 showed no sign of its radical cation $2^{\circ}$ at $-70{ }^{\circ} \mathrm{C}$, without or with trifluoroacetic acid $\left(0.8 \mathrm{~mol} \mathrm{dm}^{-3}\right)$ present. Evidently, both reaction (2) and the $\mathrm{ArH}^{\circ}+-\mathrm{NO}_{2}$ reaction are very fast under these conditions. In neat TFA at $-12^{\circ} \mathrm{C}$, irradiation of 2 and tetranitromethane again failed to produce an EPR spectrum of $2^{\circ}$; however, when the light was switched off, a weak EPR spectrum of a radical cation formed by further transformation of $2^{\circ},(1,2,4,5,6,8 \text {-hexamethylanthracene })^{\circ}$, slowly developed. The formation of this radical cation was previously ${ }^{12}$ demonstrated in the oxidation of $\mathbf{1 0}$ in trifluoroacetic acid, either photochemically or by 2,3-dichloro-4,5-dicyanobenzoquinone (DDQ). The same radical cation was also obtained and detected by EPR spectroscopy ${ }^{13}$ by irradiation of 2-tetranitromethane-trifluoroacetic acid $\left(0.4 \mathrm{~mol} \mathrm{dm}^{-3}\right)$ in HFP at $22^{\circ} \mathrm{C}$.

Attempts were also made to detect the putative $\mathrm{Ar}-\mathrm{NO}$ intermediate from the $2-\mathrm{NO}_{2}$ reaction in HFP. A solution of $\mathrm{NO}_{2}\left(5 \mathrm{mmol} \mathrm{dm}{ }^{-3}\right)$ and $2\left(100 \mathrm{mmol} \mathrm{dm}^{-3}\right)$ in 

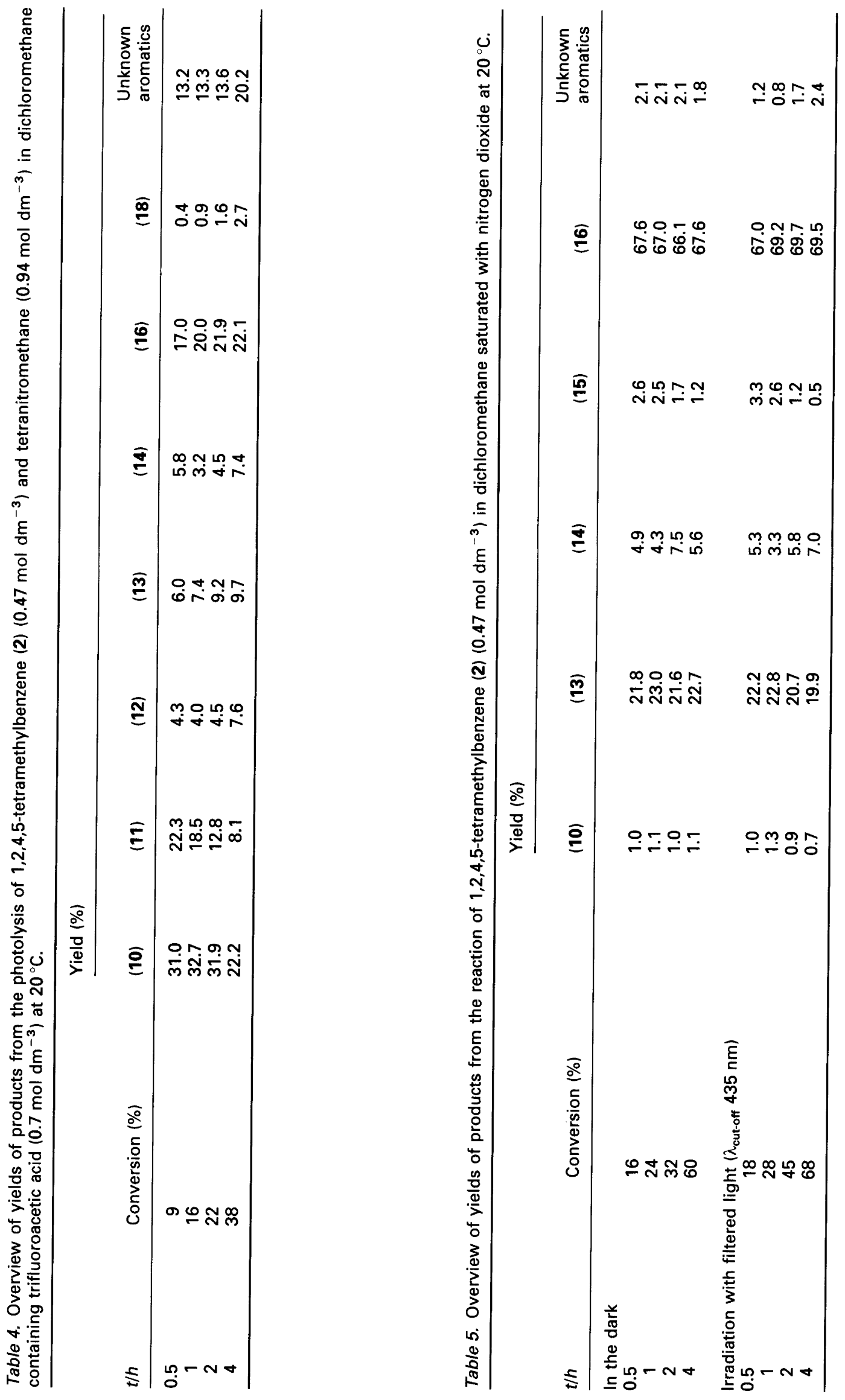
HFP was allowed to stand at $22^{\circ} \mathrm{C}$ for $10 \mathrm{~min}$, after which time $\mathrm{Tl}^{\mathrm{III}}$ trifluoroacetate was added (this procedure is known to convert 2,3,5,6-tetramethylnitrosobenzene into its radical cation ${ }^{13}$ ). However, the thermal reaction with the $T l^{\text {III }}$ reagent gave no EPR signal; only irradiation by UV light caused the EPR spectrum of $(2,3,5,6 \text {-tetramethylnitrosobenzene })^{\circ+}$ to appear. The same spectrum was obtained in the same way when the reagents were added in the reverse order, i.e. 2 was first treated with $\mathrm{Tl}^{\mathrm{III}}$ trifluoroacetate for $10 \mathrm{~min}$ and then $\mathrm{NO}_{2}$ was added.

Photochemistry of 1,2,3,5-tetramethylbenzene 7 in dichloromethane at $20^{\circ} \mathrm{C}$ and the identification of aromatic compounds 26-29, adduct 30 and 'double adducts' 31 and 32. Photolysis of the CT complex of 7-tetranitromethane in dichloromethane for $6 \mathrm{~h}$ at $20^{\circ} \mathrm{C}$, as above, gave a mixture of 2,4,6-trimethyl-1-(2',2',2'-trinitroethyl ) benzene (26, 10\%), 2,3,4,6-tetramethylnitrobenzene (27, 24\%), 3,4,5-trimethylphenylnitromethane $(28,6 \%), 2,3,5$-trimethylphenylnitromethane $(29,9 \%)$, trans-1,3,5,6-tetramethyl-6-nitro-3-trinitromethylcyclohexa-1, 4-diene (30, 14\%), the isomeric 1,2,4,6-tetramethyl-2,5-dinitro6-trinitromethylcyclohex-3-en-1-ols (31, 2\%) and (32, $1.5 \%$ ), unidentified adducts (total $18 \%$ ) and unidentified aromatic compounds (total 16\%). This mixture was partially separated into its components by chromatography on a silica gel Chromatotron plate. The first compound eluted was 2,4,6-trimethyl-1-(2', $2^{\prime}, 2^{\prime}-$ trinitroethyl) benzene (26), $\mathrm{C}_{11} \mathrm{H}_{13} \mathrm{~N}_{3} \mathrm{O}_{6}$, the structure of which was determined for a crystal of poor quality by single-crystal X-ray analysis; a perspective drawing is presented in Fig. 2, and the corresponding atomic coordinates are given in Table 6 . The structure consists of two crystallographically independent molecules, the two molecules differing in the orientation of the aromatic ring (see superposition, Fig. 3); this difference is of no chemical significance. The spectroscopic data for the trinitromethyl compound $\mathbf{2 6}$ were in accord with the established structure.

2,3,4,6-Tetramethylnitrobenzene 27 and 3,4,5-trimethylphenylnitromethane 28 were identified by comparison with authentic material. ${ }^{14}$ 2,3,5-Trimethylphenylnitromethane 29 could not be isolated in a pure state, but its structure was established by the results of nuclear Overhauser experiments and reverse-detected heteronuclear correlation spectra (HMQC) (Experimental section).

The structure of the next compound eluted was determined by single-crystal X-ray analysis. A pers-
Table 6. Fractional coordinates for atoms in 2,4,6-trimethyl$1-\left(2^{\prime}, 2^{\prime}, 2^{\prime}\right.$-trinitroethyl)-benzene (26). ${ }^{a}$

\begin{tabular}{|c|c|c|c|c|}
\hline Atom & $10^{4} X / a$ & $10^{4} Y / b$ & $10^{4} Z / c$ & $10^{3} U / \AA^{2}$ \\
\hline \multicolumn{5}{|c|}{ Molecule 1} \\
\hline$O(11)$ & $9152(3)$ & $6551(6)$ & $315(2)$ & $57(1)$ \\
\hline$O(12)$ & $9466(3)$ & $7883(5)$ & $1176(2)$ & $55(1)$ \\
\hline$O(21)$ & $6798(3)$ & $5932(5)$ & $-37(2)$ & $46(1)$ \\
\hline$O(22)$ & $7376(3)$ & $7966(5)$ & $-337(2)$ & $47(1)$ \\
\hline$O(31)$ & $6523(3)$ & $9077(5)$ & $757(2)$ & $54(1)$ \\
\hline$O(32)$ & $8045(4)$ & $9832(6)$ & $1033(3)$ & $87(2)$ \\
\hline$N(1)$ & $8899(3)$ & $7278(5)$ & $738(2)$ & $36(1)$ \\
\hline$N(2)$ & $7266(3)$ & $7063(5)$ & $63(2)$ & $30(1)$ \\
\hline$N(3)$ & $7442(4)$ & $8925(5)$ & $864(2)$ & $39(1)$ \\
\hline$C(1)$ & $7997(4)$ & $6403(5)$ & $1938(2)$ & $23(1)$ \\
\hline$C(2)$ & $7605(4)$ & $7280(5)$ & $2384(2)$ & $23(1)$ \\
\hline$c(3)$ & $8098(4)$ & $7315(5)$ & $3019(2)$ & $26(1)$ \\
\hline C(4) & $8972(4)$ & $6505(5)$ & $3233(2)$ & $24(1)$ \\
\hline$C(5)$ & $9320(3)$ & $5613(5)$ & $2787(2)$ & $25(1)$ \\
\hline$c(6)$ & $8862(3)$ & $5541(5)$ & $2142(2)$ & $24(1)$ \\
\hline$C(7)$ & $7460(4)$ & $6296(5)$ & $1240(2)$ & $25(1)$ \\
\hline$C(8)$ & $6651(4)$ & $8167(6)$ & $2208(3)$ & $33(1)$ \\
\hline$C(9)$ & $9502(4)$ & $6579(6)$ & $3926(2)$ & $35(1)$ \\
\hline$C(10)$ & $9299(4)$ & $4509(6)$ & $1704(2)$ & $33(1)$ \\
\hline$C(11)$ & $7778(4)$ & $7367(5)$ & $759(2)$ & $24(1)$ \\
\hline \multicolumn{5}{|c|}{ Molecule 2} \\
\hline$O\left(11^{\prime}\right)$ & $3218(3)$ & $5524(4)$ & $1464(2)$ & $41(2)$ \\
\hline $\mathrm{O}\left(12^{\prime}\right)$ & $1760(3)$ & $5499(5)$ & $827(2)$ & $50(1)$ \\
\hline$O\left(21^{\prime}\right)$ & $1307(3)$ & $8590(5)$ & $186(2)$ & $60(1)$ \\
\hline$O\left(22^{\prime}\right)$ & $2273(3)$ & $7095(5)$ & $-239(2)$ & $49(1)$ \\
\hline$O\left(31^{\prime}\right)$ & $3852(3)$ & $8975(5)$ & $421(2)$ & $51(1)$ \\
\hline $\mathrm{O}\left(32^{\prime}\right)$ & $4445(3)$ & $6963(5)$ & $857(2)$ & $60(1)$ \\
\hline$N\left(1^{\prime}\right)$ & $2568(3)$ & $6044(5)$ & $1050(2)$ & $32(1)$ \\
\hline$N\left(2^{\prime}\right)$ & $2030(4)$ & $7805(5)$ & $208(2)$ & $39(1)$ \\
\hline$N\left(3^{\prime}\right)$ & $3781(3)$ & $7837(5)$ & $701(2)$ & $33(1)$ \\
\hline$C\left(1^{\prime}\right)$ & $3021(3)$ & $8518(5)$ & $2056(2)$ & $22(1)$ \\
\hline$C\left(2^{\prime}\right)$ & $3895(4)$ & $9353(5)$ & $2267(2)$ & $25(1)$ \\
\hline$C\left(3^{\prime}\right)$ & $4359(4)$ & $9264(5)$ & $2910(2)$ & $26(1)$ \\
\hline$C\left(4^{\prime}\right)$ & $3996(4)$ & $8377(5)$ & $3350(2)$ & $26(1)$ \\
\hline$C\left(5^{\prime}\right)$ & $3124(4)$ & $7584(5)$ & $3133(2)$ & $25(1)$ \\
\hline$C\left(6^{\prime}\right)$ & $2621(4)$ & $7640(5)$ & $2498(2)$ & $25(1)$ \\
\hline$C\left(7^{\prime}\right)$ & $2459(4)$ & $8670(6)$ & $1363(2)$ & $26(1)$ \\
\hline$C\left(8^{\prime}\right)$ & $4348(4)$ & $10400(6)$ & $1835(3)$ & $35(1)$ \\
\hline$C\left(9^{\prime}\right)$ & $4524(4)$ & $8274(7)$ & $4041(2)$ & $38(1)$ \\
\hline$C\left(10^{\prime}\right)$ & $1660(4)$ & $6766(6)$ & $2331(3)$ & $32(1)$ \\
\hline$C\left(11^{\prime}\right\rangle$ & $2721(4)$ & $7599(6)$ & $864(2)$ & $29(1)$ \\
\hline
\end{tabular}

The equivalent isotropic temperature factor in Tables 7 and 8 is defined as one-third of orthogonalized $U_{i j}$ tensor $\left(\AA^{2}\right)$.

pective drawing of trans-1,3,5,6-tetramethyl-6-nitro3-trinitromethylcyclohexa-1,4-diene $\left(30, \mathrm{C}_{11} \mathrm{H}_{14} \mathrm{~N}_{4} \mathrm{O}_{8}\right)$ is presented in Fig. 4, and the corresponding atomic coordinates are given in Table 7. The structure consists of two crystallographically independent molecules. The differences between the two molecules lie both in the conforma-<smiles>Cc1cc([N+](=O)[O-])cc([N+](=O)[O-])c1Cc1cc([N+](=O)[O-])cc([N+](=O)[O-])c1C</smiles><smiles>CC1=C[C@@](C)([N+](=O)[O-])C=C([N+](=O)[O-])C1([N+](=O)[O-])[N+](=O)[O-]</smiles><smiles>CC1(O)C([N+](=O)[O-])=CC([N+](=O)[O-])C([N+](=O)[O-])([N+](=O)[O-])C1(C)O</smiles>

31 isomer (a) 32 isomer (b) 


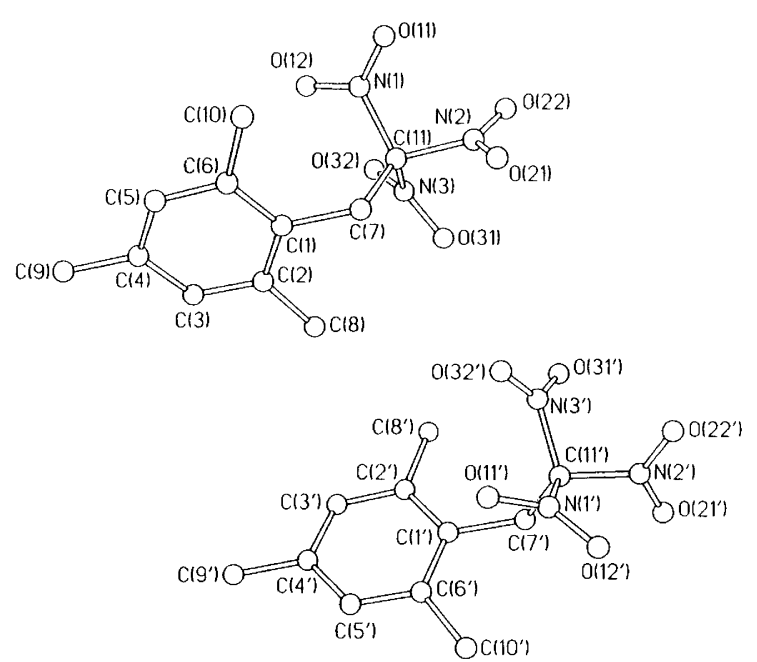

Fig. 2. Perspective drawing of compound 26.

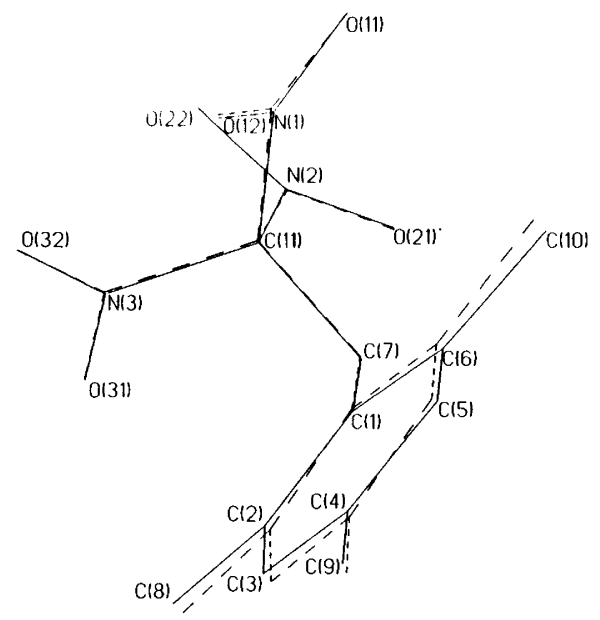

Fig. 3. Superposition of molecules 1 and 2 of compound 26.

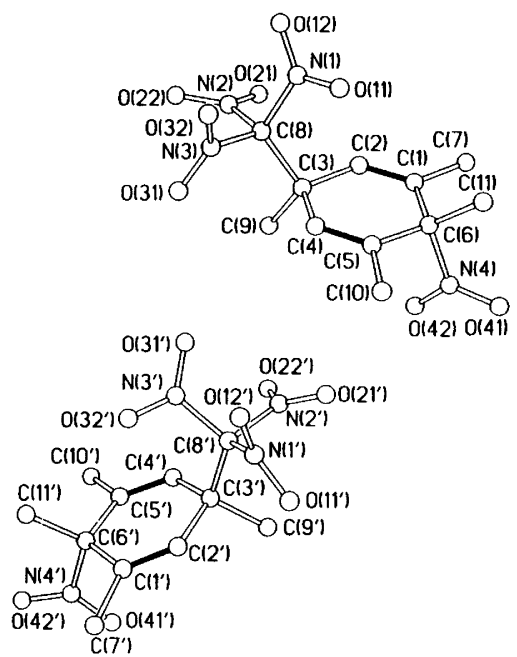

Fig. 4. Perspective drawing of compound 30. Double bonds are shown in black.
Table 7. Fractional coordinates for atoms in trans$1,3,5,6$ - tetramethyl - 6 - nitro - 3 - trinitromethylcyclohexa1,4-diene (30).

\begin{tabular}{|c|c|c|c|c|}
\hline Atom & $10^{4} X / a$ & $10^{4} Y / b$ & $10^{4} Z / c$ & $10^{3} U / \AA^{2}$ \\
\hline \multicolumn{5}{|c|}{ Molecule 1} \\
\hline$O(11)$ & $7798(2)$ & $11246(2)$ & $3895(2)$ & $49(1)$ \\
\hline$O(12)$ & $6363(2)$ & $12315(2)$ & $3413(2)$ & $53(1)$ \\
\hline$O(21)$ & $4493(2)$ & $10710(2)$ & $1251(2)$ & $50(1)$ \\
\hline$O(22)$ & $3108(2)$ & $11110(2)$ & $2421(2)$ & $70(1)$ \\
\hline$O(31)$ & $3663(2)$ & $9795(2)$ & $3597(2)$ & $54(1)$ \\
\hline $\mathrm{O}(32)$ & $5247(3)$ & $11259(2)$ & $4768(2)$ & $57(1)$ \\
\hline$O(41)$ & $9914(3)$ & $6837(2)$ & $1819(2)$ & $89(1)$ \\
\hline$O(42)$ & $7621(2)$ & $6721(1)$ & $1081(2)$ & $45(1)$ \\
\hline$N(1)$ & $6641(2)$ & $11429(2)$ & $3445(2)$ & $35(1)$ \\
\hline$N(2)$ & $4208(3)$ & $10784(2)$ & $2113(2)$ & $42(1)$ \\
\hline$N(3)$ & $4687(2)$ & $10519(2)$ & $3840(2)$ & $37(1)$ \\
\hline$N(4)$ & $8785(3)$ & $7242(2)$ & $1731(2)$ & $40(1)$ \\
\hline$C(1)$ & $8228(3)$ & $9030(2)$ & $1695(2)$ & $30(1)$ \\
\hline$C(2)$ & $6936(3)$ & $9394(2)$ & $1625(2)$ & $29(1)$ \\
\hline$C(3)$ & $5837(2)$ & $9281(2)$ & $2260(2)$ & $27(1)$ \\
\hline$C(4)$ & $6491(3)$ & $8851(2)$ & $3116(2)$ & $28(1)$ \\
\hline$C(5)$ & $7783(3)$ & $8489(2)$ & $3226(2)$ & $28(1)$ \\
\hline$C(6)$ & $8806(3)$ & $8529(2)$ & $2505(2)$ & $30(1)$ \\
\hline$C(7)$ & $9201(3)$ & $9081(2)$ & $951(2)$ & $46(1)$ \\
\hline$C(8)$ & $5358(3)$ & $10455(2)$ & $2880(2)$ & $29(1)$ \\
\hline$C(9)$ & $4468(3)$ & $8440(2)$ & $1405(2)$ & $39(1)$ \\
\hline$C(10)$ & $8280(3)$ & $7993(2)$ & $4050(2)$ & $43(1)$ \\
\hline$C(11)$ & $10387(3)$ & $9018(3)$ & $3199(3)$ & $57(1)$ \\
\hline \multicolumn{5}{|c|}{ Molecule 2} \\
\hline$O\left(11^{\prime}\right)$ & $5589(2)$ & $4732(1)$ & $3840(2)$ & $39(1)$ \\
\hline$O\left(12^{\prime}\right)$ & $5159(2)$ & $6431(2)$ & $4656(2)$ & $51(1)$ \\
\hline$O\left(21^{\prime}\right)$ & $5936(2)$ & $5832(2)$ & $2428(2)$ & $50(1)$ \\
\hline $\mathrm{O}\left(22^{\prime}\right)$ & $3876(2)$ & $5539(2)$ & $1178(2)$ & $49(1)$ \\
\hline$O\left(31^{\prime}\right)$ & $3076(2)$ & $7100(2)$ & $2998(2)$ & $54(1)$ \\
\hline $\mathrm{O}\left(32^{\prime}\right)$ & $2010(2)$ & $6201(2)$ & $3739(2)$ & $48(1)$ \\
\hline$O\left(41^{\prime}\right)$ & $-694(2)$ & $1692(2)$ & $1118(2)$ & $58(1)$ \\
\hline $\mathrm{O}\left(42^{\prime}\right)$ & $-2612(2)$ & $2381(2)$ & $1570(2)$ & $65(1)$ \\
\hline$N\left(1^{\prime}\right)$ & 4928(2) & $5510(2)$ & $3869(2)$ & $31(1)$ \\
\hline$N\left(2^{\prime}\right)$ & $4603(2)$ & $5605(2)$ & $2069(2)$ & $33(1)$ \\
\hline$N\left(3^{\prime}\right)$ & $2845(2)$ & $6308(2)$ & $3202(2)$ & $36(1)$ \\
\hline$N\left(4^{\prime}\right)$ & $-1299(2)$ & $2463(2)$ & $1613(2)$ & $38(1)$ \\
\hline$C\left(1^{\prime}\right)$ & $1028(3)$ & $3473(2)$ & $3024(2)$ & $30(1)$ \\
\hline$C\left(2^{\prime}\right)$ & $2392(2)$ & $3764(2)$ & $3004(2)$ & $28(1)$ \\
\hline$C\left(3^{\prime}\right)$ & $2775(2)$ & $4153(2)$ & $2171(2)$ & $25(1)$ \\
\hline$C\left(4^{\prime}\right)$ & $1397(2)$ & $4211(2)$ & $1375(2)$ & $25(1)$ \\
\hline$C\left(5^{\prime}\right)$ & $15(2)$ & $3955(2)$ & $1391(2)$ & $27(1)$ \\
\hline$C\left(6^{\prime}\right)$ & $-319(2)$ & $3641(2)$ & 2291(2) & $29(1)$ \\
\hline$C\left(7^{\prime}\right)$ & $776(3)$ & $2973(3)$ & $3810(2)$ & $48(1)$ \\
\hline$C\left(8^{\prime}\right)$ & $3736(2)$ & $5339(2)$ & $2804(2)$ & $27(1)$ \\
\hline$C\left(9^{\prime}\right)$ & $3670(3)$ & $3297(2)$ & $1476(2)$ & $32(1)$ \\
\hline$C\left(10^{\prime}\right)$ & $-1287(3)$ & $3976(2)$ & $511(2)$ & $38(1)$ \\
\hline$C\left(11^{\prime}\right)$ & $-1219(3)$ & $4446(2)$ & $2983(2)$ & $49(1)$ \\
\hline
\end{tabular}

tions of the alicyclic rings [torsional angles: molecule 1 , $\mathrm{C}(1)-\mathrm{C}(2)-\mathrm{C}(3)-\mathrm{C}(4) 8.3(3)^{\circ} ; \mathrm{C}(2)-\mathrm{C}(1)-\mathrm{C}(6)-\mathrm{C}(5)$ $-0.9(3)^{\circ}$. molecule $2, \quad \mathrm{C}\left(1^{\prime}\right)-\mathrm{C}\left(2^{\prime}\right)-\mathrm{C}\left(3^{\prime}\right)-\mathrm{C}\left(4^{\prime}\right)$ $\left.-9.1(3)^{\circ} ; \mathrm{C}\left(2^{\prime}\right)-\mathrm{C}\left(1^{\prime}\right)-\mathrm{C}\left(6^{\prime}\right)-\mathrm{C}\left(5^{\prime}\right) 11.1(3)^{\circ}\right]$ and in the orientations of the trinitromethyl groups relative to the alicyclic rings [torsional angles: molecule 1, $\mathrm{N}(2)-\mathrm{C}(8)-\mathrm{C}(3)-\mathrm{C}(9)-40.1(3)^{\circ}$. molecule 2 , $\left.\mathrm{N}\left(2^{\prime}\right)-\mathrm{C}\left(8^{\prime}\right)-\mathrm{C}\left(3^{\prime}\right)-\mathrm{C}\left(9^{\prime}\right) \quad 41.4(2)^{\circ}\right]$. These differences are not chemically significant. The spectroscopic data for the adduct 30 were consistent with the established structure. 
The isomeric 'double' adducts $\mathbf{3 1}$ and $\mathbf{3 2}$ were eluted in the later fractions from the HPLC column as slightly impure oils which could not be induced to crystallize. Although extensive spectroscopic data are available (Experimental section) and the implied connectivity appears certain, the stereochemistry of the two isomers could not be assigned. However, it is clear that the two isomers 31 and 32 are 'double' adducts, i.e. products derived by addition of nitrogen dioxide to initially formed hydroxytrinitromethyl- or nitrotrinitromethylcyclohexa-1,3-dienes (Ref. 5).

Photochemistry of 1,2,3,5-tetramethylbenzene (7) in dichloromethane at -20 or $-50^{\circ} \mathrm{C}$. Photolysis of the CT complex of 7-tetranitromethane in dichloromethane for $6 \mathrm{~h}$ at -20 or $-50^{\circ} \mathrm{C}$, as above, gave mixtures of products, the composition of which are summarized in Table 8.

Photochemistry of 1,2,3,5-tetramethylbenzene (7) in 1,1,1,3,3,3-hexafluoropropan-2-ol (HFP) at $20^{\circ} \mathrm{C}$. Photolysis of the CT complex of 7-tetranitromethane in HFP for $1 \mathrm{~h}$ at $20^{\circ} \mathrm{C}$, as above, resulted in a $30 \%$ conversion into predominantly 1,2,3,5-tetramethylnitrobenzene $(27,76 \%)$, together with minor amounts of compounds 26 and 28-32, and other unidentified aromatic compounds (total $7 \%$ ) and unidentified adducts (total 9\%).

Photochemistry of 1,2,3,5-tetramethylbenzene (7) in dichloromethane containing trifluoroacetic acid $(0.7 \mathrm{M})$ at $20^{\circ} \mathrm{C}$. Photolysis of the CT complex of 7-tetranitromethane in dichloromethane containing trifluoroacetic acid $(0.7 \mathrm{M})$ for $1 \mathrm{~h}$ at $20^{\circ} \mathrm{C}$, as above, resulted in a $30 \%$ conversion into predominantly 1,2,3,5-tetra methylnitrobenzene $27(56 \%)$, together with lesser amounts of compounds $26(3 \%), 28(5 \%), 29(3 \%)$, traces of compounds 30-32, and other unidentified aromatic compounds (total $7 \%$ ) and unidentified adducts (total 9\%).

Photolysis of 1,2,3,5-tetramethylbenzene 7 in acetonitrile at 20 or $-20^{\circ} \mathrm{C}$. Photolysis of the CT complex of 7-tetranitromethane in acetonitrile at either 20 or $-20^{\circ} \mathrm{C}$, as above, for $6 \mathrm{~h}$ resulted in the formation of the products 26-32 (Table 9).

Reaction of 1,2,3,5-tetramethylbenzene (7) with nitrogen dioxide in 1,1,1,3,3,3-hexafluoropropan-2-ol (HFP) at $20^{\circ} \mathrm{C}$. A solution of 7 in HFP saturated with nitrogen dioxide was irradiated with filtered light $\left(\lambda_{\text {cut-off }} 435 \mathrm{~nm}\right)$ at $20^{\circ} \mathrm{C}$. A similar mixture was stored in the dark at $20^{\circ} \mathrm{C}$. After $2 \mathrm{~h}$, after which time all of 7 in both reactions had been consumed, the excess nitrogen dioxide and solvent were removed under reduced pressure at $\leqslant 0{ }^{\circ} \mathrm{C}$. The product compositions, determined by ${ }^{1} \mathrm{H}$ NMR spectral analysis, were similar, viz. 27 (ca. 43\%), 28 (ca. 13\%), 29 (ca. 3\%), 33 (12\%), and unidentified compounds.

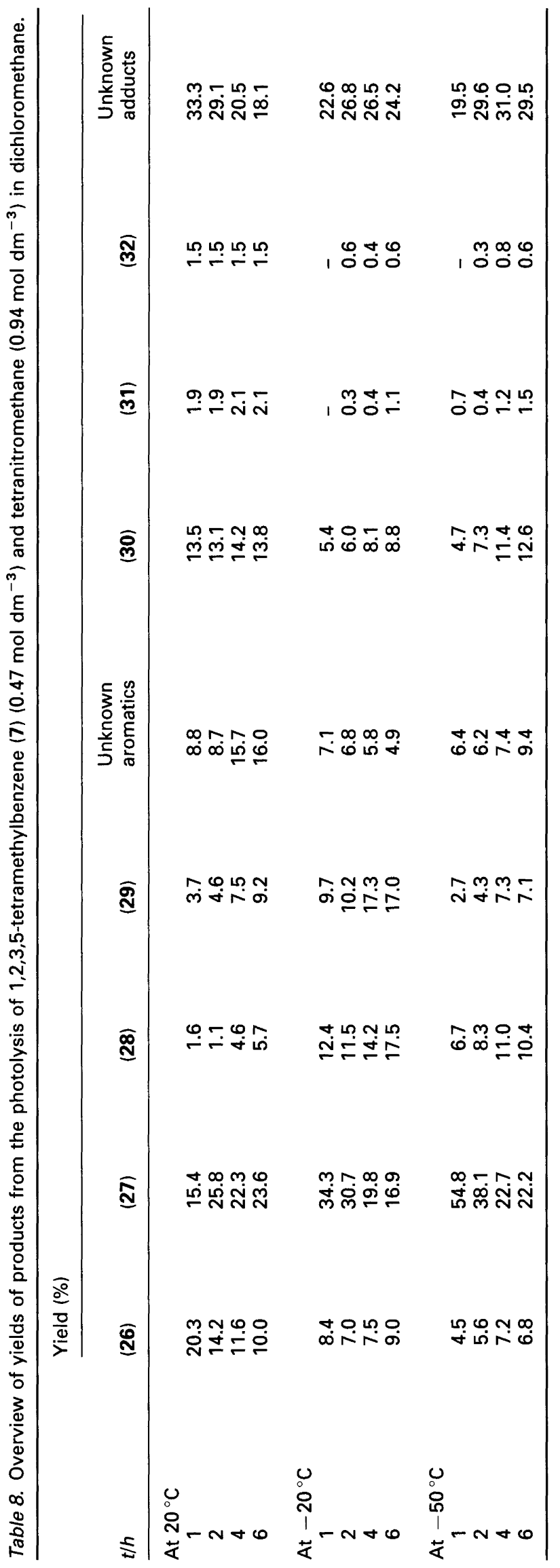




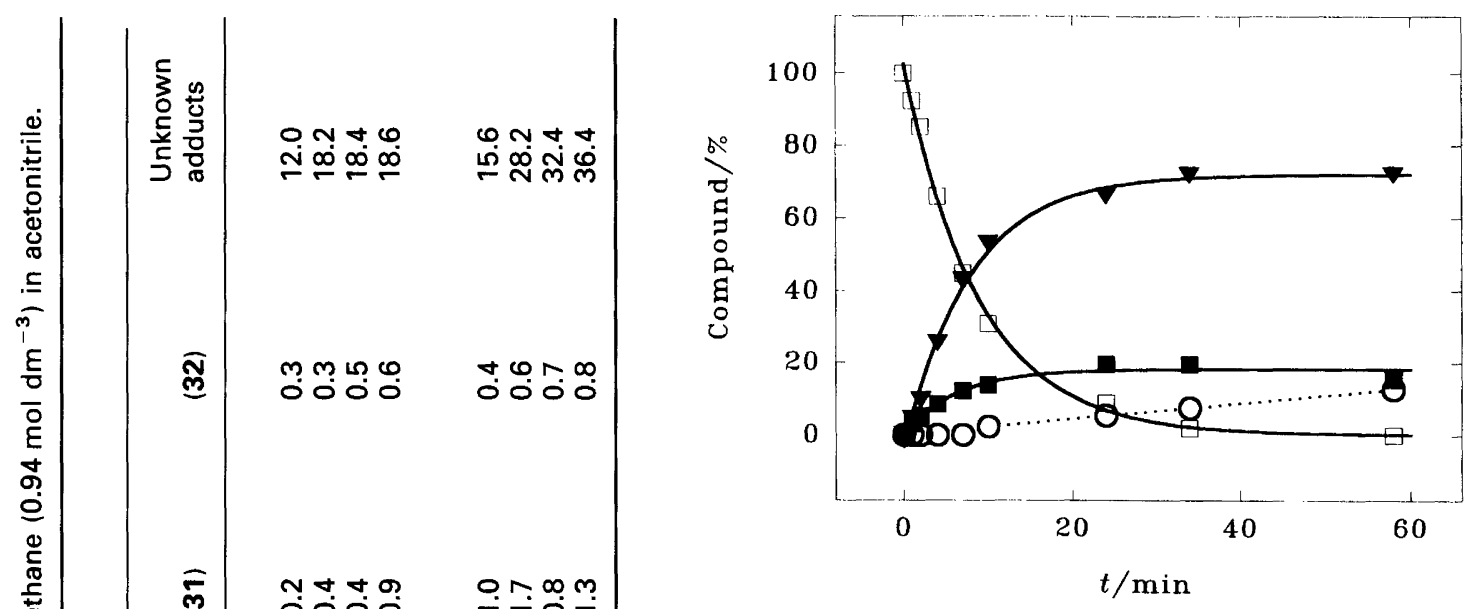

Fig. 5. Kinetics of rearrangement of adduct 30 in $\left({ }^{2} \mathrm{H}_{3}\right)$ acetonitrile at $22^{\circ} \mathrm{C}$. Empty squares, 30; filled squares, 26; triangles, 28; circles, unidentified compounds. The solid lines represent the best fits to first-order expressions with rate constants as given in the text. The dotted line is only intended for improving readability.

Eliminative rearrangement of trans-1,3,5,6-tetramethyl6-nitro-3-trinitromethylcyclohexa-1,4-diene (30) in $\left.{ }^{2} \mathrm{H}_{3}\right]$ acetonitrile at $22^{\circ} \mathrm{C}$. A solution of 30 in $\left[{ }^{2} \mathrm{H}_{3}\right]$ acetonitrile was stored at $22{ }^{\circ} \mathrm{C}$ and the ${ }^{1} \mathrm{H}$ NMR spectrum monitored at appropriate time intervals. Adduct 30 decomposed with a rate constant of $0.114(4) \mathrm{h}^{-1}$ and the major product, formed with a rate constant of $0.13(1) \mathrm{h}^{-1}$, was 3,4,5-trimethylphenylnitromethane (28). In the later stages of the rearrangement process, 2,4,6-trimethyl-1- $\left(2^{\prime}, 2^{\prime}, 2^{\prime}-\right.$ trinitroethyl)benzene (26) appeared among the products (Fig. 5) with a rate constant of $0.16(3) \mathrm{h}^{-1}$.

Attempted eliminative rearrangement of trans-1,3,5,6tetramethyl-6-nitro-3-trinitromethylcyclohexa-1,4-diene (30) in $\left[{ }^{2} \mathrm{H}\right]$ chloroform or in $\left[{ }^{2} \mathrm{H}_{2}\right]$ dichloromethane at $22{ }^{\circ} \mathrm{C}$. Solutions of $\mathbf{3 0}$ in either $\left[{ }^{2} \mathrm{H}\right]$ chloroform or $\left.{ }^{2} \mathrm{H}_{2}\right]$ dichloromethane were unchanged over a period of 4 days at $22^{\circ} \mathrm{C}$.

\section{Discussion}

The formation of adducts in the photolysis of the CT complexes of tetranitromethane with 1,2,4,5-tetramethylbenzene (2) and 1,2,3,5-tetramethylbenzene (7). Although the epimeric 1,3,4,6-tetramethyl-3-nitro-6-trinitromethylcyclohexa-1,4-dienes 8 and 9 were detected among the photolysis products of the CT complex of tetranitromethane and 2 in both dichloromethane and acetonitrile solution at $20^{\circ} \mathrm{C}$, the yields of these labile adducts 8 and 9 were considerably higher at lower reaction temperatures, reaching a total yield of $53 \%$ in dichloromethane at $-50^{\circ} \mathrm{C}$. In acetonitrile solution lower reaction temperatures were limited to $-20^{\circ} \mathrm{C}$ (total yield of adducts $15 \%$ ) because of the limited solubility of the substrate $\mathbf{2}$ in that medium. The pattern of adduct yields found for photolyses in dichloromethane 
or acetonitrile solution (Tables 1 and 3 ) is understandable in the light of the rearrangement of the nitro-trinitromethyl adducts 8 and 9 in acetonitrile and $\left[{ }^{2} \mathrm{H}\right]$ chloroform at ca. $20^{\circ} \mathrm{C}$, the rearrangement of nitro-trinitromethyl adduct 8 being complete in $1 \mathrm{~h}$ in acetonitrile (half-life ca. $0.1 \mathrm{~h}$ ) but considerably slower in $\left[{ }^{2} \mathrm{H}\right]$ chloroform (half-life ca. $72 \mathrm{~h}$ ). These rates of rearrangement of nitro-trinitromethyl adduct 8 probably reflect lower limits for the rates of rearrangement during the photolysis reactions of the CT complex of 2 with tetranitromethane; cf. results of the photolysis of the CT complex of tetranitromethane with 1,2,3-trimethylbenzene. $^{5}$

The rearrangement of adduct 8 to aromatic products, with initial equilibration to its epimer 9 and nitrites 22a and 23a, is analogous to the rearrangement of the 1,4-nitro-trinitromethyl adduct of 1,4-dimethylnaphthalene, previously studied in some detail. ${ }^{15}$ In this case it was concluded that the epimerization would occur in a polar step, whereas the nitro-nitrito rearrangement probably was of radical nature. The characteristics of the 8 rearrangement are similar and the same conclusions are probably valid.

In contrast to the marked lability of the nitro-trinitromethyl adducts 8 and 9, the nitro-trinitromethyl adduct $\mathbf{3 0}$ and the 'double' adducts $\mathbf{3 1}$ and $\mathbf{3 2}$ obtained from 7 were relatively stable in solution. Adduct $\mathbf{3 0}$ was stable in $\left[{ }^{2} \mathrm{H}\right]$ chloroform or $\left[{ }^{2} \mathrm{H}_{2}\right]$ dichloromethane at $22{ }^{\circ} \mathrm{C}$ for 4 days and rearranged in $\left[{ }^{2} \mathrm{H}_{3}\right]$ acetonitrile with a halflife of $6.0 \mathrm{~h}$ at $22^{\circ} \mathrm{C}$ (Fig. 5). Accordingly, adduct yields from 7 were significant even at $20^{\circ} \mathrm{C}$ in both dichloromethane and acetonitrile.

The addition of a protic acid to photolyses of chargetransfer complexes of aromatic molecules with tetranitromethane has been shown to convert trinitromethanide ion, one component of the triad $\left[\mathrm{ArH}^{\circ}\left(\mathrm{O}_{2} \mathrm{~N}\right)_{3} \mathrm{C}^{-}\right.$ $\mathrm{NO}_{2}$ ], into the less nucleophilic nitroform, resulting in the predominant recombination process $\mathrm{ArH}^{\circ} / \mathrm{NO}_{2}$ being observed. ${ }^{11,13}$ The photolysis of the CT complex of $\mathbf{2}$ in dichloromethane containing trifluoroacetic acid $(0.7 \mathrm{M})$ at $20^{\circ} \mathrm{C}$ proceeded more slowly than the reaction without added acid and gave aromatic compounds 10-14, 16 and 18, but adducts 8 and 9 were not detected.

It should be noted that 2,4,5-trimethyl-1- $\left(2^{\prime}, 2^{\prime}, 2^{\prime}-\right.$ trinitroethyl) benzene (11) was still formed in reasonable yield (Tables 1 and 4 ), in spite of the fact that the trinitromethanide ion concentration has been almost completely suppressed by protonation. However, since the side-chain products must be derived from the 2,4,5-trimethylbenzyl cation, it is reasonable to assume that nitroform can react as a nucleophile with this carbocation with its higher charge density at a single carbon, compared to the situation in $2^{\circ}$.

Similar reaction of 1,2,3,5-tetramethylbenzene (7) resulted in a marked reduction in the yields of the trinitromethyl derivatives 26, and 30-32, and a substantial increase in the yield of 2,3,4,6-tetramethylnitrobenzene 27, presumably as the result of $\mathrm{ArH}^{\circ+} / \mathrm{NO}_{2}$ coupling.
Reaction chemistry in 1,1,1,3,3,3-hexafluoropropan-2-ol (HFP). HFP has been found to strongly stabilize radical cations, ${ }^{16}$ partly by rendering any nucleophilic species present exceedingly unreactive. ${ }^{16 \mathrm{e}}$ We therefore anticipated that in the present work HFP would inhibit the attack of trinitromethanide ion on the radical cation and by default favour the occurrence of the $\mathrm{ArH}^{\circ} / \mathrm{NO}_{2}$ coupling process. In the event, the photolysis of the CT complex of tetranitromethane with 2 in $\mathrm{HFP}$ at $20^{\circ} \mathrm{C}$ was slow, yielded no adducts $\mathbf{8}$ and $\mathbf{9}$, a limited yield of the trinitromethyl side-chain derivative 11, and 2,3,5,6-tetramethylnitrobenzene (12) as the major product (ca. 60\%) (Table 2).

Reaction of 2 with a saturated solution of nitrogen dioxide in HFP, either on irradiation with filtered light $\left(\lambda_{\text {cut-off }} 435 \mathrm{~nm}\right)$ or in the dark at $20^{\circ} \mathrm{C}$, was complete in $<0.5 \mathrm{~h}$ and gave 2,3,5,6-tetramethylnitrobenzene 12 as the major product (ca. 74\%) and 2,3,5,6-tetramethyl-1,4-dinitrobenzene $(25,4 \%)$ as a minor product. This result is in marked contrast to the outcome of the analogous reactions of 2 with a saturated solution of nitrogen dioxide in dichloromethane at $20^{\circ} \mathrm{C}$, either on irradiation with filtered light $\left(\lambda_{\text {cut-off }} 435 \mathrm{~nm}\right)$ or in the dark, in which $2,4,5$-trimethylbenzyl nitrate $(16$, ca. $70 \%)$ and 2,4,5-trimethylphenylnitromethane (13, ca. $20 \%)$ were the significant products. It appears that the 'dark' and 'light' reaction conditions of the reactions of nitrogen dioxide in dichloromethane, above, have resulted in thermal nitration of $\mathbf{2}$, the product composition being broadly in agreement with product ratios for thermal nitration using nitrogen dioxide in dichloromethane in the dark reported recently by Bosch and Kochi. ${ }^{10}$

In contrast, the formation of ring-substituted nitration products 12 and 33 in the reactions of 2 with nitrogen dioxide in HFP is consistent with the reaction sequence of nitrosation (by $\mathrm{NO}^{+}$), followed by oxidation of the nitrosoarene to the nitroarenes; it seems probable that the 1,4-dinitro compound $\mathbf{3 3}$ is formed by sequential nitrosation of 1,2,4,5-tetramethylbenzene (2), followed by oxidation of the 1,4-dinitroso compound 34 .

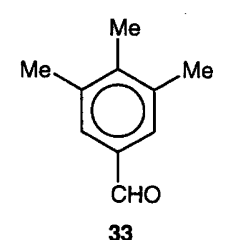

33

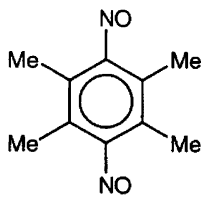

34
What then is the role of HFP in promoting the nitrosation of 1,2,4,5-tetramethylbenzene (2)? Bosch and $\mathrm{Kochi}^{10}$ recently proposed the following equilibrium [eqn. (4)] arising in the interaction between the 'head-totail' coupled form of nitrogen dioxide and an aromatic molecule.

$\mathrm{ONO}-\mathrm{NO}_{2} \rightleftharpoons \mathrm{NO}^{+} \mathrm{NO}_{3}{ }^{-} \stackrel{\mathrm{ArH}}{\rightleftharpoons}\left[\mathrm{ArH}, \mathrm{NO}^{+}\right] \mathrm{NO}_{3}{ }^{-}$

Given the propensity of HFP for essentially sequestering 
nucleophilic species, it appears likely that the effect of HFP in promoting aromatic nitrosation arises from its effect on the equilibrium in eqn. (4) in favour of the $\left[\mathrm{ArH}, \mathrm{NO}^{+}\right]$species with the counter-ion $\mathrm{NO}_{3}{ }^{-}$deactivated by interaction with the solvent.* Under these circumstances, and in the presence of excess nitrogen dioxide in HFP, nitrosation appears the likely reaction, as is found.

Returning now to the consideration of the outcome of the photolysis of the CT complex of 2 with tetranitromethane in HFP which results in extensive ring nitration, it appears that not only does HFP markedly reduce the nucleophilic reactivity of trinitromethanide ion, but also promotes nitrosation of $\mathrm{ArH}$ by nitrogen dioxide, as outlined above. In this connection, it should be noted that the conversion of $\mathbf{2}$ into products in this photolysis reaction with tetranitromethane in HFP is a slow process (Table 2 ).

The reactions of 1,2,3,5-tetramethylbenzene (7) in HFP, either of the photolysis of the charge-transfer complex with tetranitromethane or 'light' or 'dark' reactions with excess nitrogen dioxide, broadly parallel those reported above for 2 , i.e. a substantial increase in overall ring nitration to give 2,3,4,6-tetramethylnitrobenzene (27).

The EPR spectroscopic results and their implications. The radical cation of 1,2,4,5-tetramethylbenzene, $2^{+}$, is a very reactive species which has only been detected in solution by EPR spectroscopy using $\mathrm{Co}^{\text {III }}$ trifluoroacetate as the oxidant in a flow method, ${ }^{17}$ or using either $\mathrm{Hg}^{\mathrm{II}}$ trifluoroacetate UV irradiation ${ }^{18}$ at low temperature or $\mathrm{Tl}^{\mathrm{III}}$ trifluoroacetate oxidation ${ }^{19}$ at ambient temperature as methods of generation. The success of the latter method probably depends on the fact that the EPR experiment actually monitors the slow formation of the radical cation, as demonstrated for hexamethylbenzene radical cation. ${ }^{20}$ Thus the experiments designed to use photolysis of 2-tetranitromethane in the presence of trifluoroacetic acid failed to produce any detectable concentrations of $\mathbf{2}^{\circ}$. However, since the photolysis reaction gives $\mathbf{1 0}$ as one of the products, most likely via the reaction sequence shown in eqn. (5), ${ }^{21}$ it still becomes possible to indirectly observe the consequences of the formation of $\mathbf{2}^{\circ}$; the oxidation of $\mathbf{1 0}$ will produce the 1,2,4,5,6,8-hexamethylanthracene radical cation which gives a characteristic EPR spectrum. ${ }^{12}$ It should be noted that this radical cation is sensitive toward the light used in the photolysis and is therefore best observed immediately after the light has been switched off (see Experimental).

\footnotetext{
* The reaction between nitrate ion and the tris(4-bromophenyl)aminium ion in HFP is very slow, ${ }^{16 \mathrm{~g}}$ as expected slower than those of chloride and bromide ion $\left(k \approx 10^{-4} \mathrm{dm}^{3}\right.$ $\left.\mathrm{mol}^{-1} \mathrm{~s}^{-1}\right){ }^{16 \mathrm{e}}$
}

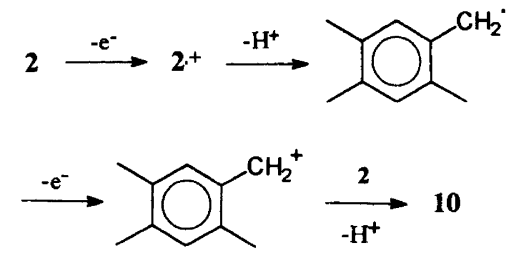

Thus weak spectra of the 1,2,4,5,6,8-hexamethylanthracene radical cation were observed from the photolysis of 2 and tetranitromethane in both neat trifluoroacetic acid at $-12^{\circ} \mathrm{C}$ and HFP-trifluoroacetic acid $\left(0.4 \mathrm{~mol} \mathrm{dm}^{-3}\right)$ at $22^{\circ} \mathrm{C}$, implying that the acidic medium protonates trinitromethanide ion und thus leaves $2^{\circ}$ to engage in competing, slower reactions.

The experiments designed to possibly detect 2,3,5,6-tetramethylnitrosobenzene as its radical cation from the reaction between 2 and $\mathrm{NO}_{2}$ in HFP cannot be unambiguously interpreted. The EPR spectrum of the nitroso compound was indeed detected, but since the reaction between an arylthallium(III) trifluoroacetate and $\mathrm{NO}_{2}$ is a synthetic pathway to nitrosoarenes, ${ }^{22,23}$ it is not possible to know with certainty which sequence of events has led to the appearance of the EPR spectra observed.

\section{Experimental}

Melting points are uncorrected. Infrared spectra were recorded on a Perkin Elmer 1600 Series FTIR spectrometer; ${ }^{1} \mathrm{H}$ and ${ }^{13} \mathrm{C}$ NMR spectra were recorded on a Varian Unity 300 spectrometer with $\mathrm{SiMe}_{4}$ as an internal standard. HPLC separations were carried out on a Varian 5000 liquid chromatograph equipped with an Alltech cyanopropyl column, and using a Varian UV-50 ultraviolet spectrometric detector and hexane-dichloromethane as solvent mixtures. Tetranitromethane, 1,2,4,5- and 1,2,3,5-tetramethylbenzene were purchased from Aldrich. Dichloromethane (AR) and acetonitrile (HiPerSolv) were from $\mathrm{BDH}$ and 1,1,1,3,3,3-hexafluoropropan-2-ol from Sigma or of Merck UVASOL quality.

WARNING. While we did not experience any incidents in working with tetranitromethane, it should be noted that its mixtures with hydrocarbons are detonative within certain concentration limits and that due care should be taken in handling mixtures of tetranitromethane and organic molecules. ${ }^{24}$

General procedure for the photonitration of 1,2,4,5-tetramethylbenzene (2) and 1,2,3,5-tetramethylbenzene (7) with tetranitromethane. A solution of 2 or $7(500 \mathrm{mg}, 0.47 \mathrm{~mol}$ $\left.\mathrm{dm}^{-3}\right)$ and tetranitromethane $\left(0.94 \mathrm{~mol} \mathrm{dm}^{-3}\right)$ in dichloromethane (at $20,-20$ or $-50^{\circ} \mathrm{C}$ ), acetonitrile $\left(20\right.$ or $\left.-20^{\circ} \mathrm{C}\right)$, or $1,1,1,3,3,3$-hexafluoropropan-2-ol $\left(20^{\circ} \mathrm{C}\right)$ was irradiated with filtered light $\left(\lambda_{\text {cut-off }} 435 \mathrm{~nm}\right)$. Aliquots were withdrawn from the reaction mixture at appropriate time intervals, the volatile material removed under reduced pressure at $\leqslant 0{ }^{\circ} \mathrm{C}$, and the product composition determined by NMR spectral analysis (Tables 1-4, 7 and 10). 
Table 10. Nuclear Overhauser effects for compounds isolated.

\begin{tabular}{|c|c|c|}
\hline Compound & $\begin{array}{l}\text { Irradiated } \\
\text { at } \delta(\mathrm{ppm})\end{array}$ & $\begin{array}{l}\text { Enhancement(s) (\%) } \\
\text { at } \delta(p p m)\end{array}$ \\
\hline 8 & $\begin{array}{l}1.74 \\
1.80 \\
1.87 \\
1.96 \\
5.82 \\
6.20\end{array}$ & $\begin{array}{l}5.82(4.0) \\
6.20(4.4) \\
5.82(4.9) \\
6.20(4.1) \\
1.74(0.3) ; 1.87(0.7) \\
1.80(0.7) ; 1.96(0.2)\end{array}$ \\
\hline 9 & $\begin{array}{l}1.74 \\
1.85 \\
1.87 \\
1.94 \\
5.98 \\
6.28\end{array}$ & $\begin{array}{l}1.94(0.5) ; 5.98(5.2) \\
6.28(3.6) \\
5.98(3.9) \\
6.28(3.2) \\
1.74(0.6) ; 1.87(0.9) \\
1.94(1.3)\end{array}$ \\
\hline 10 & $\begin{array}{l}2.04 \\
2.06 \\
2.18 \\
2.27 \\
2.36 \\
3.87 \\
6.28 \\
6.94 \\
6.97\end{array}$ & $\begin{array}{l}6.28(7.2) \\
2.27(1.1) ; 3.87(6.4) \\
6.97(5.0) \\
2.06(1.4) ; 6.94(9.0) \\
3.87(3.4) ; 6.97(5.5) \\
2.06(2.6) ; 2.36(2.9) \\
2.04(1.0) \\
2.27(1.7) \\
2.18(1.0) ; 2.36(1.2)\end{array}$ \\
\hline 11 & $\begin{array}{l}2.17 \\
2.18 \\
2.21 \\
4.38 \\
6.82 \\
7.00\end{array}$ & $\begin{array}{l}4.38(1.3) ; 7.00(4.1) \\
6.82(3.9) \\
7.00(3.8) \\
2.17(1.6) ; 6.82(4.0) \\
2.18(0.6) ; 4.38(0.6) \\
2.17(0.6) ; 2.21(0.2)\end{array}$ \\
\hline 12 & $\begin{array}{l}2.25 \\
7.04\end{array}$ & $\begin{array}{l}7.04(4.4) \\
2.25(0.3)\end{array}$ \\
\hline 13 & $\begin{array}{l}2.23 \\
2.31 \\
5.41 \\
7.02 \\
7.10\end{array}$ & $\begin{array}{l}7.02(2.3) ; 7.10(2.7) \\
5.41(0.8) ; 7.02(2.5) \\
2.31(0.5) ; 7.10(3.6) \\
2.23(0.2) ; 2.31(0.5) \\
5.41(0.7)\end{array}$ \\
\hline 14 & $\begin{array}{r}2.29 \\
2.60 \\
7.03 \\
7.55 \\
10.19\end{array}$ & $\begin{array}{l}7.03(2.3) ; 7.55(2.3) \\
7.03(2.3) ; 10.19(1.7) \\
2.29(0.1) ; 2.60(0.3) \\
2.29(0.2) ; 10.19(2.0) \\
2.60(0.2) ; 7.55(1.4)\end{array}$ \\
\hline 15 & $\begin{array}{l}2.22 \\
2.28 \\
4.61 \\
6.95 \\
7.08\end{array}$ & $\begin{array}{l}6.95(2.5) ; 7.08(2.3) \\
4.61(0.6) ; 6.95(2.2) \\
2.28(0.3) ; 7.08(2.1) \\
2.22(0.4) ; 2.28(0.4) \\
2.22(0.1) ; 4.61(0.4)\end{array}$ \\
\hline 18 & $\begin{array}{l}2.08 \\
2.11 \\
2.36 \\
3.88 \\
6.20 \\
6.99\end{array}$ & $\begin{array}{l}6.20(6.5) \\
3.88(4.1) ; 2.196 .99(5.0) \\
3.88(2.1) ; 6.99(5.9) \\
2.11(2.6) ; 2.36(2.5) ; 6.20(1.7) \\
2.08(1.2) \\
2.19(0.4) ; 2.36(1.2)\end{array}$ \\
\hline 19 & $\begin{array}{l}2.13 \\
2.16 \\
2.31 \\
4.86 \\
6.50 \\
6.90\end{array}$ & $\begin{array}{l}6.50(4.2) \\
6.90(3.5) \\
4.86(1.3) ; 6.90(3.7) \\
2.31(1.2) ; 6.50(2.7) \\
2.13(0.9) ; 4.86(0.5) \\
2.16(0.6) ; 2.31(0.8)\end{array}$ \\
\hline
\end{tabular}

Table 10. (continued).

\begin{tabular}{lll}
\hline Compound & $\begin{array}{l}\text { Irradiated } \\
\text { at } \delta(\mathrm{ppm})\end{array}$ & $\begin{array}{l}\text { Enhancement(s) (\%) } \\
\text { at } \delta(\mathrm{ppm})\end{array}$ \\
\hline 26 & 2.17 & $4.70(2.8) ; 6.88(3.9)$ \\
& 2.26 & $6.88(4.2)$ \\
& 4.70 & $2.17(1.8)$ \\
& 6.88 & $2.17(1.1) ; 2.26(1.1)$ \\
& & \\
29 & 5.43 & $2.32(0.4) ; 7.10(3.3)$ \\
& 7.03 & $2.24(0.3)$ \\
& 7.10 & $2.24(0.4) ; 5.43(0.7)$ \\
30 & 1.79 & $5.94(7.7)$ \\
& 5.94 & $1.79(0.5)$ \\
31 & 1.26 & $4.93(3.1)$ \\
& 1.34 & $4.93(5.1)$ \\
& 1.95 & $6.24(3.5)$ \\
& 2.07 & $4.94(2.2) ; 6.24(3.5)$ \\
& 4.93 & $1.26(0.7) ; 1.34(0.6) ; 2.07(0.6)$ \\
& 6.24 & $1.95(0.4) ; 2.07(0.5)$ \\
32 & 1.29 & $4.94(3.8)$ \\
& 1.31 & $1.90(1.1) ; 4.94(4.9)$ \\
& 1.90 & $1.29(0.5) ; 1.31(0.8) ; 6.10(3.8)$ \\
& 2.11 & $1.29(0.5) ; 4.94(4.1) ; 6.10(3.7)$ \\
& 4.94 & $1.29(0.7) ; 1.31(0.5) ; 2.11(0.7)$ \\
& 6.10 & $1.29(0.5) ; 1.90(0.5) ; 2.11(0.6)$ \\
\hline
\end{tabular}

Photochemistry of 1,2,4,5-tetramethylbenzene (2) in dichloromethane at $-50{ }^{\circ} \mathrm{C}$ and the identification of adducts 8 and 9. Reaction of 2-tetranitromethane in dichloromethane at $-50^{\circ} \mathrm{C}$, as above, for $4 \mathrm{~h}$ gave a product which was shown by ${ }^{1} \mathrm{H}$ NMR spectra to be a mixture of adducts $8(46 \%)$ and $9(7 \%)$, aromatic compounds 10-17 (total 41\%), and unidentified aromatic products $(6 \%)$. The mixture was partially separated into its components by HPLC and gave the following in elution order:

The first material eluted was a mixture of aromatic compounds.

1,3,4,6-Tetramethyl-r-3-nitro-t-6-trinitromethylcyclohexa1,4-diene (8), as an unstable oil (elemental analysis not possible because of instability; parent ion not visible in mass spectrum). IR: $v_{\max }$ (liquid film) 1599, 1583, $1549 \mathrm{~cm}^{-1} .{ }^{1} \mathrm{H}$ NMR $\left(\mathrm{CDCl}_{3}\right) \delta 1.74(\mathrm{~s}, 3-\mathrm{Me}), 1.80(\mathrm{~d}$, $\left.J_{4-\mathrm{Me}, \mathrm{H} 5} 1.5 \mathrm{~Hz}, 4-\mathrm{Me}\right), 1.87$ (d, $\left.J_{1-\mathrm{Me}, \mathrm{H} 2} 1.5 \mathrm{~Hz}, 1-\mathrm{Me}\right)$, $1.96(\mathrm{~s}, 6-\mathrm{Me}), 5.82\left(\mathrm{q}, J_{\mathrm{H} 2,1-\mathrm{Me}} 1.5 \mathrm{~Hz}, \mathrm{H} 2\right), 6.20$ (q, $\left.J_{\mathrm{H} 5,4-\mathrm{Me}} 1.5 \mathrm{~Hz}, \mathrm{H} 5\right)$. Nuclear Overhauser experiments, see Table 10. ${ }^{13} \mathrm{C}$ NMR $\left(\mathrm{CDCl}_{3}\right) \delta 18.3$ (4-Me), 19.1 (1-Me), 23.3 (3-Me, 6-Me), 51.2 (C6), 88.3 (C3), 126.0 (C5), 130.2 (C2), $134.1(\mathrm{C} 1), 136.2(\mathrm{C} 4)$, resonance for $\mathrm{C}\left(\mathrm{NO}_{2}\right)_{3}$ not observed. The above assignments were confirmed by long-range reverse-detected heteronuclear correlation spectra (HMBC,HMQC).

1,3,4,6-Tetramethyl-r-3-nitro-c-6-trinitromethylcyclohexa-1,4-diene (9), as an oil in admixture with adduct (8) $(5 \%) .{ }^{1} \mathrm{H}$ NMR $\left(\mathrm{CDCl}_{3}\right) \delta 1.74(\mathrm{~s}, 3-\mathrm{Me}), 1.85(\mathrm{~s}$, 6-Me), 1.87 (d, J-Me, н2 $1.5 \mathrm{~Hz}, 1-\mathrm{Me}) .1 .94$ (d, $J_{4-\mathrm{Me}, \mathrm{H} 5}$ 
$1.5 \mathrm{~Hz}, 4-\mathrm{Me}), 5.98$ (q, $\left.J_{\mathrm{H} 2,1-\mathrm{Me}} 1.5 \mathrm{~Hz}, \mathrm{H} 2\right), 6.28$ (q, $\left.J_{\mathrm{H} 5,4-\mathrm{Me}} 1.5 \mathrm{~Hz}, \mathrm{H} 5\right)$. Nuclear Overhauser experiments, see Table 10. ${ }^{13} \mathrm{C}$ NMR $\left(\mathrm{CDCl}_{3}\right) \delta 18.7$ (4-Me), 18.9, 23.7 (1-Me, 6-Me), 25.6 (3-Me), 50.6 (C6), 85.4 (C3), $126.4(\mathrm{C} 5), 130.3(\mathrm{C} 2), 134.4(\mathrm{Cl}), 136.3(\mathrm{C} 4)$, resonance for $\mathrm{C}\left(\mathrm{NO}_{2}\right)_{3}$ not observed. The above assignments were confirmed by long-range reverse-detected heteronuclear correlation spectra (HMBC,HMQC), and comparison with data for the epimer 8.

Photochemistry of 1,2,4,5-tetramethylbenzene (2) in 1,1,1,3,3,3-hexafluoropropan-2-ol (HFP) at $20^{\circ} \mathrm{C}$ and the identification of the aromatic products (10-16 and 18). Reaction of 2-tetranitromethane in $\mathrm{HFP}$ at $20^{\circ} \mathrm{C}$, as above, gave a mixture of the aromatic compounds 10-16 and 18 (Table 2). Chromatography of the crude product on a silica gel Chromatotron plate allowed the separation of aromatic compounds 10-15 and 18, compound 16 not being eluted from the plate, in elution order:

$2,2^{\prime}, 3,4^{\prime}, 5,5^{\prime}, 6$-Heptamethyldiphenylmethane (10), m.p. $139^{\circ} \mathrm{C}$ (decomp.) (Found: $M^{+}$266.2034. $\mathrm{C}_{20} \mathrm{H}_{26}$ requires 266.20345). ${ }^{1} \mathrm{H}$ NMR $\left(\mathrm{CDCl}_{3}\right) \delta 2.04\left(\mathrm{~s}, 5^{\prime}-\mathrm{Me}\right)$, 2.06 (s, 6H, 2-Me, 6-Me), 2.18 (s, 4'-Me), 2.27 (s, 6H, 3-Me, 5-Me), 2.36 (s, 2'-Me), 3.87 (s, $\mathrm{CH}_{2}$ ), 6.28 (s, $\left.\mathrm{H6}^{\prime}\right), 6.94$ (s, H4), 6.97 (s, H3'), identical with an authentic sample available from earlier work. ${ }^{20}$ Nuclear Overhauser experiments, see Table $10 .{ }^{13} \mathrm{C}$ NMR $\left(\mathrm{CDCl}_{3}\right) \delta 15.7$ (2-Me, 6-Me), 19.1, 19.2 (2'-Me, 4'-Me), 19.3 (5'-Me), 20.6 (3-Me, 5-Me), $32.7\left(\mathrm{CH}_{2}\right), 127.9$ (C6), 129.8 (C4), $131.2\left(\mathrm{C}^{\prime}\right), 133.2,133.5$ (C2, C3, C5, C5', C6), $133.8\left(\mathrm{C}^{\prime}\right), 135.3\left(\mathrm{C}^{\prime}\right), 136.7$ (C1). The above assignments were confirmed by long-range reversedetected heteronuclear correlation spectra (HMQC, HMBC).

2,4,5-Trimethyl-1-(2',2',2'-trinitroethyl $)$ benzene

(11), m.p. $70-73{ }^{\circ} \mathrm{C}$ (insufficient for elemental analysis; Found: $M^{+}$283.0804. $\mathrm{C}_{11} \mathrm{H}_{13} \mathrm{~N}_{3} \mathrm{O}_{6}$ requires 283.0804). IR: $v_{\max }$ ( $\mathrm{KBr}) 1605,1578 \mathrm{~cm}^{-1}$. ${ }^{1} \mathrm{H}$ NMR $\left(\mathrm{CDCl}_{3}\right) \delta 2.17(\mathrm{~s}$, 2-Me), 2.18 (s, 5-Me), 2.21 (s, 4-Me), 4.38 (br s, $\mathrm{CH}_{2}$ ), 6.82 (s, H6), 7.00 (s, H3). Nuclear Overhauser experiments, see Table $10 .{ }^{13} \mathrm{C}$ NMR $\left(\mathrm{CDCl}_{3}\right) \delta 18.6(5-\mathrm{Me})$, 19.2 (4-Me), 19.4 (2-Me), $36.3\left(\mathbf{C H}_{2}\right), 122.4(\mathrm{Cl}$ or $\mathrm{C} 2)$, 130.4 (C6), 132.7 (C3), 135.4 (C2 or C1, and $\mathrm{C} 4$ or $\mathrm{C} 5$ ), 138.3 (C5 or $\mathrm{C} 4)$, resonance for $\mathrm{C}\left(\mathrm{NO}_{2}\right)_{3}$ not observed. The above assignments were confirmed by long-range reverse-detected heteronuclear correlation spectra (HMBC, HMQC).

2,3,5,6-Tetramethylnitrobenzene (12), m.p. 109-114 ${ }^{\circ} \mathrm{C}$, identical with an authentic sample. ${ }^{25}$ IR: $v_{\max }(\mathrm{KBr})$ $1520 \mathrm{~cm}^{-1}$. ${ }^{1} \mathrm{H}$ NMR $\left(\mathrm{CDCl}_{3}\right) \delta 2.12(\mathrm{~s}, 6 \mathrm{H}, 2-\mathrm{Me}$, 6-Me), 2.25 (s, 6H, 3-Me, 5-Me), 7.04 (s, H4). Nuclear Overhauser experiments, see Table 10.

2,4,5-Trimethylphenylnitromethane (13), ${ }^{3}$ isolated as an oil (Found: $M^{+}$179.0944. $\mathrm{C}_{10} \mathrm{H}_{13} \mathrm{NO}_{2}$ requires 179.0946). IR: $v_{\max }$ (liquid film) $1543,1369 \mathrm{~cm}^{-1} .{ }^{1} \mathrm{H}$ NMR $\left(\mathrm{CDCl}_{3}\right) \delta 2.23$ (s, 6H, 4-Me, 5-Me), 2.31 (s,
2-Me), 5.41 (s, CH ), 7.02 (s, H3), 7.10 (s, H6). Nuclear Overhauser experiments, see Table 10.

2,2',3,4',5,5'6-Heptamethyl-4-nitrodiphenylmethane (18), m.p. $157^{\circ} \mathrm{C}$ (decomp.) (insufficient for elemental analysis. Found: $M^{+}$311.1885. $\mathrm{C}_{20} \mathrm{H}_{25} \mathrm{NO}_{2}$ requires 311.1885). IR: $v_{\max }(\mathrm{KBr}) 1524 \mathrm{~cm}^{-1} .{ }^{1} \mathrm{H}$ NMR $\left(\mathrm{CDCl}_{3}\right) \delta 2.08(\mathrm{~s}$, 5'-Me), 2.11 (s, 6H, 2-Me, 6-Me), 2.19 (s, 9H, 3-Me, 4'-Me, 5-Me), 2.36 (s, 2'-Me), 3.88 (s, $\mathrm{CH}_{2}$ ), 6.20 (s, $\left.\mathrm{H6}^{\prime}\right), 6.99$ (s, H3'). Nuclear Overhauser experiments, see Table 10. ${ }^{13} \mathrm{C} \mathrm{NMR}\left(\mathrm{CDCl}_{3}\right) \delta 15.0$ (3-Me or 4'-Me), 16.2 (2-Me), 19.1 (2'-Me and $4^{\prime}-\mathrm{Me}$ or $\left.3-\mathrm{Me}\right), 19.3$ (5'-Me), $33.1\left(\mathrm{CH}_{2}\right), 127.5\left(\mathrm{C6}^{\prime}\right), 131.4\left(\mathrm{C}^{\prime}\right), 133.2\left(\mathrm{Cl}^{\prime}\right.$ or $\left.\mathrm{C2}^{\prime}\right), 133.9\left(\mathrm{C2}^{\prime}\right.$ or $\left.\mathrm{Cl}^{\prime}\right), 135.1(\mathrm{C} 2), 138.9(\mathrm{C} 1)$, signals due to $\mathrm{C} 3, \mathrm{C} 4, \mathrm{C4}^{\prime}$ and $\mathrm{C5}^{\prime}$ could not be assigned. The above assignments were confirmed by long-range reversedetected heteronuclear correlation spectra (HMBC, HMQC).

2,4,5-Trimethylbenzaldehyde (14), isolated as an oil (Found: $M^{+}$148.0886. $\mathrm{C}_{10} \mathrm{H}_{12} \mathrm{O}$ requires 148.0888 . Fragmentation pattern identical with an authentic sample). IR: $v_{\max }$ (liquid film) $2754,1697 \mathrm{~cm}^{-1} \cdot{ }^{1} \mathrm{H}$ NMR $\left(\mathrm{CDCl}_{3}\right) \delta 2.29(\mathrm{~s}, 6 \mathrm{H}, 4-\mathrm{Me}, 5-\mathrm{Me}), 2.60(\mathrm{~s}$, 2-Me), 7.03 (s, H3), 7.55 (s, H6), 10.19 (s, CHO). Nuclear Overhauser experiments, see Table 10.

2,4,5-Trimethylbenzyl alcohol (15), isolated as an oil (Found: $M^{+}$150.1040. $\mathrm{C}_{10} \mathrm{H}_{14} \mathrm{O}$ requires 150.1045 . Fragmentation pattern identical with an authentic sample). IR: $v_{\max }$ (liquid film) $3379 \mathrm{~cm}^{-1} \cdot{ }^{1} \mathrm{H}$ NMR $\left(\mathrm{CDCl}_{3}\right) \delta 2.22$ (s, 6H, 4-Me, 5-Me), 2.28 (s, 2-Me), 4.61 (s, $\mathrm{CH}_{2}$ ), 6.95 (s, H3), 7.08 (s, H6). Nuclear Overhauser experiments, see Table 10.

2,4,5-Trimethylbenzyl nitrate (16) was not eluted from the silica gel Chromatotron plate, being presumably hydrolysed to 2,4,5-trimethylbenzyl alcohol (15). The presence of 2,4,5-trimethylbenzyl nitrate (16) in the crude reaction mixture was inferred from the ${ }^{1} \mathrm{H}$ NMR signal due to the $-\mathrm{CH}_{2}-\mathrm{ONO}_{2}$ group at $\delta 5.39 .^{3}$

Photochemistry of 1,2,4,5-tetramethylbenzene (2) in acetonitrile at $20^{\circ} \mathrm{C}$ and the identification of the N-nitroso acetamide (19). Reaction of 2-tetranitromethane in acetonitrile at $20^{\circ} \mathrm{C}$, as above, for $4 \mathrm{~h}$ gave a product which was shown by ${ }^{1} \mathrm{H}$ NMR spectra to be a mixture of aromatic compounds 10-16, and 18 (total 86\%), the $\mathrm{N}$-nitrosoacetamide $19(9 \%)$ and unidentified aromatic products $(5 \%)$ (Table 3$)$. Chromatography of the reaction mixture on a silica gel Chromatotron plate gave the $N$-nitrosoacetamide 19 in a fraction eluted immediately before 2,4,5-trimethylbenzaldehyde (14):

$N$-nitrosoacetamide (19), isolated as an oil (insufficient for elemental analysis. Found: $M^{+} 220.12105$. $\mathrm{C}_{12} \mathrm{H}_{16} \mathrm{~N}_{2} \mathrm{O}_{2}$ requires 220.1211. Found: $M^{+}-\mathrm{NO}$ 190.1227. $\mathrm{C}_{12} \mathrm{H}_{16} \mathrm{NO}$ requires 190.1227). IR: $v_{\max }$ (liquid film) $1726,1499,1128,912 \mathrm{~cm}^{-1} .{ }^{1} \mathrm{H}$ NMR $\left(\mathrm{CDCl}_{3}\right) \delta$ 2.13 (s, 5-Me), 2.16 (s, 4-Me), 2.31 (s, 2-Me), 2.85 (s, $\mathrm{CH}_{3}-\mathrm{CO}$ ), 4.86 (s, $\mathrm{CH}_{2}$ ), 6.50 (s, H6), 6.90 (s, H3). 
Nuclear Overhauser experiments, see Table $10 .{ }^{13} \mathrm{C}$ NMR $\left(\mathrm{CDCl}_{3}\right) \delta 18.7$ (2-Me), 19.2, 19.3 (4-Me, 5-Me), 22.8 $\left(\mathrm{CH}_{3}-\mathrm{CO}\right), 39.5\left(\mathrm{CH}_{2}\right), 127.9(\mathrm{C} 6), 129.4(\mathrm{C} 2), 131.8$ (C3), 133.0 (C1), 134.1 (C4), 135.8 (C5), 174.6 (amide $\mathbf{C}=\mathbf{O}$ ). The above assignments were confirmed by longrange reverse-detected heteronuclear correlation spectra (HMBC, HMQC).

Photochemistry of 1,2,4,5-tetramethylbenzene (2) at $20^{\circ} \mathrm{C}$ in dichloromethane containing trifluoroacetic acid $(0.7 \mathrm{~mol}$ $\left.d m^{-3}\right)$. Reaction of 2-tetranitromethane in dichloromethane containing trifluoroacetic acid $\left(0.7 \mathrm{~mol} \mathrm{dm}^{-3}\right)$ at $20^{\circ} \mathrm{C}$, as above, for $4 \mathrm{~h}$ gave a product which was shown by ${ }^{1} \mathrm{H}$ NMR spectra to be a mixture of aromatic compounds 10-14, 16 and 18 (total 80\%), and unidentified aromatic products (20\%) (Table 4$)$.

Rearrangement of 1,3,4,6-tetramethyl-r-3-nitro-t-6trinitromethylcyclohexa-1,4-diene $(\mathbf{8})$ in acetonitrile at $20^{\circ} \mathrm{C}$. A solution of $8(11 \mathrm{mg})$ in acetonitrile $(11 \mathrm{ml})$ was stored in the dark at $20^{\circ} \mathrm{C}$. Aliquots were withdrawn from the reaction mixture at appropriate time intervals, the solvent removed under reduced pressure at $\leqslant 0{ }^{\circ} \mathrm{C}$, and the composition of each residue determined by ${ }^{1} \mathrm{H}$ NMR spectral analysis. Within the first 5 min adduct 8 underwent epimerization to give adduct 9, and also nitro-nitrito rearrangement to give the epimeric trinitromethyl nitrites 22a and 23a, equilibrium $(8: 9: 22 \mathbf{a}: 23 \mathbf{a}$ $\approx 3: 1: 4: 1$ ) between these species being reached after 3-5 min. During the workup procedure the trinitromethyl nitrites 22a and 23a were converted into the corresponding 1,2,4,5-tetramethyl-t-4-trinitromethylcyclohexa2,5-dien-r-1-ol (22b), ${ }^{1} \mathrm{H}$ NMR $\left(\mathrm{CDCl}_{3}\right) \delta 1.42$ (s, 1-Me), 1.75 (s, 4-Me), 1.78 (d, $\left.J_{2-\mathrm{Me}, \mathrm{H} 3} 1.5 \mathrm{~Hz}, 2-\mathrm{Me}\right), 1.92$ (d, $\left.J_{5-\mathrm{Me}, \mathrm{H} 6} 1.5 \mathrm{~Hz}, 5-\mathrm{Me}\right), 5.54\left(\mathrm{q}, J_{\mathrm{H} 6,5-\mathrm{Me}} 1.5 \mathrm{~Hz}, \mathrm{H} 6\right), 5.88$ (q, $J_{\mathrm{H} 3,2-\mathrm{Me}} 1.5 \mathrm{~Hz}, \mathrm{H} 3$ ), and 1,2,4,5-tetramethyl-c4-trinitromethylcyclohexa-2,5-dien-r-1-ol $\quad(\mathbf{2 3 b}), \quad{ }^{1} \mathrm{H}$ NMR $\left(\mathrm{CDCl}_{3}\right) \delta 1.32(\mathrm{~s}, 1-\mathrm{Me}), 1.69(\mathrm{~s}, 4-\mathrm{Me}), 1.76(\mathrm{br}$ s, 2-Me), 1.90 (br s, 5-Me), 5.53 (q, $J_{\mathrm{H} 6,5-\mathrm{Me}} 1.5 \mathrm{~Hz}, \mathrm{H} 6$ ), $5.84\left(\mathrm{q}, J_{\mathrm{H} 3,2-\mathrm{Me}} 1.5 \mathrm{~Hz}, \mathrm{H} 3\right)$. Subsequently over ca. $1 \mathrm{~h}$ this equilibrium mixture of adducts $8,9,22 \mathrm{a}$ and 23a was converted into a mixture of 2,4,5-trimethyl$1-\left(2^{\prime}, 2^{\prime}, 2^{\prime}\right.$-trinitroethyl $)$ benzene $\quad(11, \quad 16 \%), \quad 2,3,5,6-$ tetramethylnitrobenzene $(12,21 \%), 2,4,5$-trimethylphenylnitromethane $(13,13 \%), 2,4,5$-trimethylbenzyl alcohol (15, 9\%), 2,4,5-trimethylbenzyl nitrate $(\mathbf{1 6}, 4 \%)$, and unidentified aromatic products (total $37 \%$ ).

Rearrangement of 1,3,4,6-tetramethyl-r-3-nitro-t-6trinitromethylcyclohexa-1,4-diene (8) in $\left[{ }^{2} \mathrm{H}\right]$-chloroform at $20^{\circ} \mathrm{C}$. A solution of 8 in $\left[{ }^{2} \mathrm{H}\right]$ chloroform was stored in the dark at $20^{\circ} \mathrm{C}$, and the ${ }^{1} \mathrm{H}$ NMR spectrum of the solution was monitored at appropriate time intervals. In comparison with the rearrangement of $\mathbf{8}$ in acetonitrile, above, the transformations of 8 in $\left[{ }^{2} \mathrm{H}\right]$ chloroform occurred sluggishly, equilibrium with the epimer 9 (8:9 $\approx 6: 1$ ) being established only after ca. $90 \mathrm{~h}$, and the formation of products from the adduct mixture being complete after $>14$ days. In contrast to the rearrangement in acetonitrile, the trinitromethyl nitrites 22a and 23a were not detected in the rearrangement in $\left[{ }^{2} \mathrm{H}\right]$ chloroform. The major products present after 25 days were 2,4,5-trimethyl-1-(2',2',2'-trinitroethyl $)$ benzene $(11,52 \%), 2,4,5$-trimethylphenylnitromethane (13, $18 \%)$, 2,4,5-trimethylbenzaldehyde $(14,6 \%), 2,4,5$-trimethylbenzyl nitrate $(16,10 \%)$ and unidentified aromatic compounds $(13 \%)$.

Nitration of 1,2,4,5-tetramethylbenzene (2) with nitrogen dioxide in dichloromethane at $20^{\circ} \mathrm{C}$. A solution of 2 $\left(0.47 \mathrm{~mol} \mathrm{dm}^{-3}\right)$ in dichloromethane saturated with nitrogen dioxide was stored at $20^{\circ} \mathrm{C}$ in the dark. Aliquots were removed at appropriate time intervals, the excess nitrogen dioxide and solvent were removed under reduced pressure at $\leqslant 0^{\circ} \mathrm{C}$, and the product composition determined by ${ }^{1} \mathrm{H}$ NMR spectral analysis (Table 5). After $4 \mathrm{~h}$ the products formed were shown to be predominantly 2,4,5-trimethylbenzyl nitrate $(16,70 \%)$, and 2,4,5-trimethylphenylnitromethane $(13,20 \%)$ and small amounts of aromatic compounds 10, 14 and 15, and unidentified aromatic compounds.

Photochemical nitration of 1,2,4,5-tetramethylbenzene (2) with nitrogen dioxide in dichloromethane at $20^{\circ} \mathrm{C}$. A solution of $2\left(0.47 \mathrm{~mol} \mathrm{dm}^{-3}\right)$ in dichloromethane saturated with nitrogen dioxide was irradiated with filtered light $\left(\lambda_{\text {cut-off }} 435 \mathrm{~nm}\right)$ at $20^{\circ} \mathrm{C}$. Aliquots were removed at appropriate time intervals, the excess nitrogen dioxide and solvent were removed under reduced pressure at $\leqslant 0{ }^{\circ} \mathrm{C}$, and the product composition determined by ${ }^{1} \mathrm{H}$ NMR spectral analysis (Table 5). After $4 \mathrm{~h}$ the products formed were shown to be similar to those of the 'dark' reaction, above, i.e. predominantly 2,4,5-trimethylbenzyl nitrate (16,68\%), and 2,4,5-trimethylphenylnitromethane $(13,23 \%)$ and small amounts of aromatic compounds 10, 14 and 15, and unidentified aromatic compounds.

Nitration of 1,2,4,5-tetramethylbenzene (2) with nitrogen dioxide in 1,1,1,3,3,3-hexafluoropropan-2-ol (HFP) at $20^{\circ} \mathrm{C}$. A solution of $2\left(0.47 \mathrm{~mol} \mathrm{dm}^{-3}\right)$ in HFP saturated with nitrogen dioxide was stored at $20^{\circ} \mathrm{C}$ in the dark. Aliquots were removed at appropriate time intervals, the excess nitrogen dioxide and solvent were removed under reduced pressure at $\leqslant 0^{\circ} \mathrm{C}$, and the product composition determined by ${ }^{1} \mathrm{H}$ NMR spectral analysis. Complete reaction of 2 had occurred after $<0.5 \mathrm{~h}$ and the products formed were shown to be predominantly 2,3,5,6-tetramethylnitrobenzene $(\mathbf{1 2}, \quad 71 \%), \quad 2,4,5$-trimethylbenzoic acid (24, 18\%), 2,3,5,6-tetramethyl1,4-dinitrobenzene $(25,4 \%)$, and small amounts of aromatic compounds 13 and 14, and unidentified aromatic compounds.

Photochemical nitration of 1,2,4,5-tetramethylbenzene (2) with nitrogen dioxide in 1,1,1,3,3,3-hexafluoropropan-2-ol (HFP) at $20^{\circ} \mathrm{C}$. A solution of $2\left(0.47 \mathrm{~mol} \mathrm{dm}^{-3}\right)$ in HFP saturated with nitrogen dioxide was irradiated with 
filtered light $\left(\lambda_{\text {cut-off }} 435 \mathrm{~nm}\right)$ at $20^{\circ} \mathrm{C}$. Aliquots were removed at appropriate time intervals, the excess nitrogen dioxide and solvent were removed under reduced pressure at $\leqslant 0{ }^{\circ} \mathrm{C}$, and the product composition determined by ${ }^{1} \mathrm{H}$ NMR spectral analysis. Complete reaction of $\mathbf{2}$ had occurred after $<0.5 \mathrm{~h}$ and the products formed were shown to be similar to those of the 'dark' reaction, above, i.e. predominantly 2,3,5,6-tetramethylnitrobenzene $(12,74 \%), 2,4,5$-trimethylbenzoic acid $(24,12 \%)$, 2,3,5,6-tetramethyl-1,4-dinitrobenzene $(\mathbf{2 5}, 4 \%)$, and small amounts of aromatic compounds 13 and 14, and unidentified aromatic compounds.

Photochemistry of 1,2,3,5-tetramethylbenzene (7) in dichloromethane at $20^{\circ} \mathrm{C}$ and the identification of aromatic compounds 26-29, adduct 30 and 'double adducts' 31 and 32. Reaction of 7-tetranitromethane in dichloromethane at $20^{\circ} \mathrm{C}$, as above, for $6 \mathrm{~h}$ gave a product which was shown by ${ }^{1} \mathrm{H}$ NMR spectra to be a mixture of aromatic compounds 26-29 (total 49\%), adduct 30 (14\%), adducts 31 and 32 (total 4\%), unidentified aromatic compounds (total 16\%), and unidentified adducts (total 18\%) (Table 6). The mixture was partially separated into its components by HPLC and gave the following in elution order:

2,4,6-Trimethyl-1-(2',2',2'-trinitroethyl) benzene

(26), m.p. $83{ }^{\circ} \mathrm{C}$ (decomp.) (X-ray crystal structure determined, see below). IR: $v_{\max }(\mathrm{KBr}) 1601 \mathrm{~cm}^{-1} \cdot{ }^{1} \mathrm{H}$ NMR $\left(\mathrm{CDCl}_{3}\right) \delta 2.17$ (s, 2-Me, 6-Me), 2.26 (s, 4-Me), 4.70 (br $\mathrm{s}, \mathrm{CH}_{2}$ ), 6.88 (s, H3, H5). Nuclear Overhauser experiments, see Table $10 .{ }^{13} \mathrm{C}$ NMR $\left(\mathrm{CDCl}_{3}\right) \delta 20.0$ (2-Me, 6-Me), 20.9 (4-Me), 123.2 (C2, C6), 130.0 (C3, C5), $138.3(\mathrm{C} 1), 139.2(\mathrm{C} 4)$, resonance for $\mathbf{C}\left(\mathrm{NO}_{2}\right)_{3}$ not observed. The above assignments were confirmed by long-range reverse-detected heteronuclear correlation spectra (HMBC, HMQC).

2,3,4,6-Tetramethylnitrobenzene (27), identical with an authentic sample. ${ }^{14}$

3,4,5-Trimethylphenylnitromethane (28), identical with an authentic sample. ${ }^{14}$

2,3,5-Trimethylphenylnitromethane (29), as an oil containing an impurity (5\%). ${ }^{1} \mathrm{H}$ NMR $\left(\mathrm{CDCl}_{3}\right) \delta 2.24$ (s, 3-Me, 5-Me), 2.32 (s, 2-Me), 5.43 (s, $\mathrm{CH}_{2} \mathrm{NO}_{2}$ ), 7.03 (s, H4), 7.10 (s, H6). Nuclear Overhauser experiments, see Table 10. ${ }^{13} \mathrm{C}$ NMR $\left(\mathrm{CDCl}_{3}\right) \delta 18.4$ (2-Me), 19.0, 19.4 (3-Me, 5-Me), $77.6\left(\mathrm{CH}_{2} \mathrm{NO}_{2}\right.$ ), 132.2 (C4), 132.6 (C6); signals at $\delta 125.7,129.4,135.2,138.9$ could not be assigned. The above assignments were confirmed by longrange reverse-detected heteronuclear correlation spectra (HMQC).

trans-1,3,5,6-Tetramethyl-6-nitro-3-trinitromethylcyclohexa-1,4-diene $(30)$, m.p. $66-68^{\circ} \mathrm{C}$ (X-ray crystal structure determined, see below). IR: $v_{\max }(\mathrm{KBr}) 1583$, $1547 \mathrm{~cm}^{-1} .{ }^{1} \mathrm{H} \mathrm{NMR}\left(\mathrm{CDCl}_{3}\right) \delta 1.79$ (br s, 1-Me, 3-Me, 5-Me, 6-Me), 5.94 (br s, H2, H4). Nuclear Overhauser experiments, see Table $10 .{ }^{13} \mathrm{C}$ NMR $\left(\mathrm{CDCl}_{3}\right) \delta 18.4$
(1-Me, 5-Me), 20.6, 25.5 (3-Me, 6-Me), 47.6 (C3), 90.9 (C6), $124.1(\mathrm{C} 2, \mathrm{C} 4), 137.0(\mathrm{C} 1, \mathrm{C} 5)$, resonance for $\mathrm{C}\left(\mathrm{NO}_{2}\right)_{3}$ not observed. The above assignments were confirmed by long-range reverse-detected heteronuclear correlation spectra (HMBC, HMQC).

1,2,4,6-Tetramethyl-2,5-dinitro-6-trinitromethylcyclohex3-en-1-ol (31), isolated as an oil containing an impurity (5\%). IR: $v_{\max }$ (liquid film) $3693,1601,1560 \mathrm{~cm}^{-1} \cdot{ }^{1} \mathrm{H}$ NMR $\left(\mathrm{CDCl}_{3}\right) \delta 1.26(\mathrm{~s}, 1-\mathrm{Me}), 1.34$ (s, 6-Me), 1.95 (s, 3-Me), 2.07 (d, $\left.J_{4-\mathrm{Me}, \mathrm{H} 3} 1.5 \mathrm{~Hz}, 4-\mathrm{Me}\right), 4.93$ (s, H5), 6.24 (q, $J_{\mathrm{H} 3,4-\mathrm{Me}} 1.5 \mathrm{~Hz}, \mathrm{H} 3$ ). Nuclear Overhauser experiments, see Table 10. ${ }^{13} \mathrm{C}$ NMR $\left(\mathrm{CDCl}_{3}\right) \delta 18.6(1-\mathrm{Me}), 20.3$ (4-Me), 22.0 (2-Me), 22.3 (6-Me), 45.1 (C6), 51.7 (C1), 86.1 (C2), 96.0 (C5), 128.3 (C3), 130.2 (C4), resonance for $\mathbf{C}\left(\mathrm{NO}_{2}\right)_{3}$ not observed. The above assignments were confirmed by long-range reverse-detected heteronuclear correlation spectra (HMBC, HMQC).

1,2,4,6-Tetramethyl-2,5-dinitro-6-trinitromethylcyclohex3-en-1-ol (32), isolated as an oil containing an impurity (10\%). IR: $v_{\max }$ (liquid film) $3445,1576,1553 \mathrm{~cm}^{-1} \cdot{ }^{1} \mathrm{H}$ NMR $\left(\mathrm{CDCl}_{3}\right) \delta 1.29$ (s, 1-Me), 1.31 (s, 6-Me), 1.90 (s, 2-Me), 2.11 (d, $J_{4-\mathrm{Me} . \mathrm{H} 3} 1.5 \mathrm{~Hz}, 4-\mathrm{Me}$ ), 4.94 (s, H5), 6.10 (q, $J_{\mathrm{H} 3,4-\mathrm{Me}} 1.5 \mathrm{~Hz}, \mathrm{H} 3$. Nuclear Overhauser experiments, see Table 10. ${ }^{13} \mathrm{C}$ NMR $\left(\mathrm{CDCl}_{3}\right) \delta 20.7$ (1-Me), 22.2 (4-Me), 24.9 (6-Me), 26.2 (2-Me), 47.6 (C6), 62.3 (C1), 88.5 (C2), 96.8 (C5), 128.8 (C3), 133.4 (C4), resonance for $\mathbf{C}\left(\mathrm{NO}_{2}\right)_{3}$ not observed. The above assignments were confirmed by long-range reverse-detected heteronuclear correlation spectra (HMBC, HMQC).

Photochemistry of 1,2,3,5-tetramethylbenzene (7) in 1,1,1,3,3,3-hexafluoropropan-2-ol (HFP) at $20^{\circ} \mathrm{C}$. Reaction of 7 -tetranitromethane in $\mathrm{HFP}$ at $20^{\circ} \mathrm{C}$, as above, after $1 \mathrm{~h}$ gave a mixture of the aromatic compounds $26(1 \%), 27(76 \%), 28(0.4 \%), 29(1 \%)$, adduct $30(2 \%)$, adducts $31(0.6 \%)$ and $32(2 \%)$, unidentified aromatic compounds (total $7 \%$ ), and unidentified adducts (total $9 \%$ ).

Photochemistry of 1,2,3,5-tetramethylbenzene (7) at $20^{\circ} \mathrm{C}$ in dichloromethane containing trifluoroacetic acid $(0.7 \mathrm{~mol}$ $\left.d^{-3}\right)$. Reaction of 7-tetranitromethane in dichloromethane containing trifluoroacetic acid $\left(0.7 \mathrm{~mol} \mathrm{dm}^{-3}\right)$ at $20^{\circ} \mathrm{C}$, as above, for $1 \mathrm{~h}$ gave a product which was shown by ${ }^{1} \mathrm{H}$ NMR spectra to be a mixture of the aromatic compounds 26 (3\%), $27(56 \%), 28(5 \%), 29$ $(3 \%)$, adduct $30(0.8 \%)$, adducts $31(0.4 \%)$ and 32 $(0.2 \%)$, unidentified aromatic compounds (total $14 \%$ ), and unidentified adducts (total 17\%).

Nitration of 1,2,3,5-tetramethylbenzene (7) with nitrogen dioxide in 1,1,1,3,3,3-hexafluoropropan-2-ol (HFP) at $20^{\circ} \mathrm{C}$. A solution of $7\left(0.47 \mathrm{~mol} \mathrm{dm}^{-3}\right)$ in HFP saturated with nitrogen dioxide was stored at $20^{\circ} \mathrm{C}$ in the dark. Aliquots were removed at appropriate time intervals, the excess nitrogen dioxide and solvent were removed under reduced pressure at $\leqslant 0^{\circ} \mathrm{C}$, and the product composition 
determined by ${ }^{1} \mathrm{H}$ NMR spectral analysis. Essentially complete reaction of 7 had occurred after $2 \mathrm{~h}$ and the products formed were shown to be predominantly 2,3,4,6-tetramethylnitrobenzene $\quad(27,42 \%), \quad 3,4,5-$ trimethylphenylnitromethane $(\mathbf{2 8}, 12 \%), 2,3,5$-trimethylphenylnitromethane $(29,3 \%), 3,4,5$-trimethylbenzaldehyde $(33,10 \%)$, and unidentified products $(33 \%)$.

Photochemical nitration of 1,2,3,5-tetramethylbenzene (7) with nitrogen dioxide in 1,1,1,3,3,3-hexafluoropropan-2-ol (HFP) at $20^{\circ} \mathrm{C}$. A solution of $7\left(0.47 \mathrm{~mol} \mathrm{dm}^{-3}\right)$ in HFP saturated with nitrogen dioxide was irradiated with filtered light $\left(\lambda_{\text {cut-off }} 435 \mathrm{~nm}\right)$ at $20^{\circ} \mathrm{C}$. Aliquots were removed at appropriate time intervals, the excess nitrogen dioxide and solvent were removed under reduced pressure at $\leqslant 0{ }^{\circ} \mathrm{C}$, and the product composition determined by ${ }^{1} \mathrm{H}$ NMR spectral analysis. Essentially complete reaction of $7 \mathrm{had}$ occurred after $2 \mathrm{~h}$ and the products formed were shown to be similar to those of the 'dark' reaction, above, i.e. predominantly 2,3,4,6-tetramethylnitrobenzene $(27,44 \%), 3,4,5$-trimethylphenylnitromethane (28, 13\%), 2,3,5-trimethylphenylnitromethane (29, 3\%), 3,4,5-trimethylbenzaldehyde $(33,13 \%)$, and unidentified products $(27 \%)$.

Rearrangement of trans-1,3,5,6-tetramethyl-6-nitro3-trinitromethylcyclohexa-1,4-diene (30) in $\left[{ }^{2} \mathrm{H}_{3}\right]$ acetonitrile at $22^{\circ} \mathrm{C}$. A solution of the adduct 30 in $\left[{ }^{2} \mathrm{H}_{3}\right]$ acetonitrile was stored in the dark at $22^{\circ} \mathrm{C}$ and the ${ }^{1} \mathrm{H}$ NMR spectrum monitored at appropriate time intervals. Initially $(0-7 \mathrm{~h})$ adduct 30 rearranged to give 3,4,5-trimethylphenylnitromethane (28) and some unidentified material. At longer reaction times the conversion of the adduct $\mathbf{3 0}$ into the nitromethyl compound 28 and unidentified compounds continued, but 2,4,6-trimethyl-1-(2',2',2'-trinitroethyl ) benzene (26) appeared among the products. The kinetic evaluation is presented in Fig. 4.

The attempted rearrangement of trans-1,3,5,6-tetramethyl6-nitro-3-trinitromethylcyclohexa-1,4-diene (30) in $\left[{ }^{2} \mathrm{H}\right]$ chloroform or in $\left[{ }^{2} \mathrm{H}_{2}\right]$ dichloromethane at $22^{\circ} \mathrm{C}$. Solutions of the adduct $\mathbf{3 0}$ in either $\left[{ }^{2} \mathrm{H}\right]$ chloroform or $\left[{ }^{2} \mathrm{H}_{2}\right]$ dichloromethane were stable for greater than 4 days at $22^{\circ} \mathrm{C}$.

EPR spectroscopy. EPR spectra were recorded by the Upgrade Version ESP 3220-200SH of a Bruker ER-200D spectrometer, equipped with a photolysis cavity. The light source was the $50 \mathrm{~W}$ high-pressure $\mathrm{Hg}$ lamp from Bruker (ER 202) and the filter was from Schott, Germany (cut-off at $430 \mathrm{~nm}$ ).

Control experiments established that the $\mathrm{Hg}^{\text {II }}$ trifluoroacetate-UV light ${ }^{18}\left(\right.$ at $-12^{\circ} \mathrm{C}$ ) and $\mathrm{Tl}^{\mathrm{III}}$ trifluoroacetate method ${ }^{19}$ (at -12 and $0^{\circ} \mathrm{C}$ ) gave excellent spectra of $2^{\circ}$ in neat trifluoroacetic acid or HFP, the latter solvent being used in the $0^{\circ} \mathrm{C}$ runs. As in the case of pentamethylbenzene, ${ }^{21}$ the $\mathrm{Tl}^{\mathrm{III}}$ method could be performed photochemically with advantage.
The attempts to generate and detect $2^{\circ}$ by photolysis of 2 (ca. $40 \mathrm{mmol} \mathrm{dm}^{-3}$ ) in the presence of tetranitromethane $\left(0.4 \mathrm{~mol} \mathrm{dm}^{-3}\right)$ by light of $\lambda>435 \mathrm{~nm}$ were performed in dichloromethane and dichloromethane-

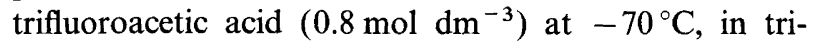
fluoroacetic acid at $-12^{\circ} \mathrm{C}$, and in HFP and HFPtrifluoroacetic acid $\left(0.4 \mathrm{~mol} \mathrm{dm}^{-3}\right)$ at $22^{\circ} \mathrm{C}$. Only in the acidic solutions was any radical cation detectable, and then in the form of the transformation product, $(1,2,4,5,6,8 \text {-hexamethylanthracene })^{\circ}$, characterized previously. ${ }^{12}$

The attempts to detect 1-nitroso-2,3,5,6-tetramethylbenzene were made on solutions of $2\left(100 \mathrm{~mol} \mathrm{dm}^{-3}\right)$ in HFP, to which a small volume (maximum $3 \%$ of the total volume) of $\mathrm{NO}_{2}$ in dichloromethane was added to

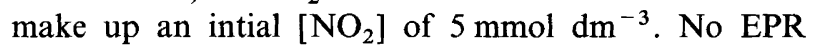
signal was detectable. After $10 \mathrm{~min} \mathrm{Tl}^{\mathrm{III}}$ trifluoroacetate was added. Again, the thermal reaction gave no EPR signal, whereas irradiation by UV light generated the EPR spectrum of (2,3,5,6-tetramethylnitrosobenzene) ${ }^{\circ}$ (Refs. 13 and 26). This spectrum disappeared immediately after discontinuation of the irradiation. Inverse addition of the reagents gave the same result.

Crystallography. Crystal data, established from precession photographs and measured accurately, by means of a Siemens $\mathrm{R} 3 \mathrm{~m} / \mathrm{V}$ four-circle diffractometer [molybdenum X-radiation, $\lambda($ Mo K $\alpha) 0.71073 \AA$ from a crystal monochromator] are given below. The space group was determined unambiguously as a result of the structure analysis reported below, but indicated initially by conditions limiting possible reflections. $\omega$-Scans were used to collect reflection intensities out to a maximum Bragg angle $\theta$, given below. The cell parameters were determined by least-squares refinements for which the setting angles of accurately centred high-angle reflections were used.

\section{Crystal data}

2,4,6-Trimethyl-1-(2',2',2'-trinitroethyl)-benzene (26), $\mathrm{C}_{11} \mathrm{H}_{13} \mathrm{~N}_{3} \mathrm{O}_{6}, M 283.24$, monoclinic, space group $P 21 / c$, $a$ 13.399(6), $b$ 9.217(4), c 20.976(8),$\beta$ 99.56(3) ; $V$ 2555(2) $\AA^{3}, D_{\mathrm{c}} 1.473 \mathrm{~g} \mathrm{~cm}^{-3}, Z 8, \mu($ Mo K $\alpha) 1.22 \mathrm{~cm}^{-1}$. The crystal was colourlesss and of approximate dimensions $1.0 \times 0.8 \times 0.4 \mathrm{~mm}$. Data were collected at $158(2)$ $\mathrm{K}$ out to a maximum Bragg angle $\theta=28.5^{\circ}$. Number of independent reflections measured 3340,2368 with $I$ $>2 \sigma(I)$. Absorption corrections were not applied; $g_{1}$ $0.1122, g_{2} 6.1900 ; R_{\text {(obs) }}$-factor $0.074, w R_{\text {(all data) }} 0.23$.

trans-1,3,5,6-Tetramethyl-6-nitro-3-trinitromethylcyclohexa-1,4-diene (30), $\mathrm{C}_{11} \mathrm{H}_{14} \mathrm{~N}_{4} \mathrm{O}_{8}, M 330.26$, triclinic, space group $P \overline{1}, a 9.344(3), b 13.228(4), c 13.459(3) \AA$, $\alpha$ 113.99(2), $\beta$ 102,68(2), $\gamma$ 92,47(2) $; V$ 1466.4(7) $\AA^{3}$, $D_{\mathrm{c}} 1.496 \mathrm{~g} \mathrm{~cm}^{-3}, Z 4, \mu($ Mo K $\alpha) 1.29 \mathrm{~cm}^{-1}$. The crystal was colourless and of approximate dimensions $0.90 \times 0.86 \times 0.84 \mathrm{~mm}$. Data were collected at $163(2) \mathrm{K}$ out to a maximum Bragg angle $\theta=25^{\circ}$. Number of 
independent reflections measured 4984, 3420 with $I$ $>2 \sigma(I)$. Absorption corrections were not applied; $g_{1}$ $0.0946, g_{2} 0.0000 ; R_{\text {(obs) }}$-factor $0.053, w R_{\text {(all data) }} 0.138$.

Structure determination. Full-matrix least-squares refinements (SHELXL-93) ${ }^{27}$ were employed. This program is based on intensities and uses all data. The observed threshold $I>2 \sigma(I)$ was used only for calculating $r_{\text {(obs) }}$, shown here as a comparison for the refinement based on $F$. Reflection weights $1 /\left[\sigma^{2}\left(F_{\mathrm{o}}{ }^{2}\right)+\left(g_{1} P\right)^{2}+g_{2} P\right]$, where $P=\left[F_{\mathrm{o}}{ }^{2}+2 F_{\mathrm{c}}{ }^{2}\right] / 3$, were used. All non-hydrogen atoms were assigned anisotropic thermal parameters. Methyl hydrogens were included as rigid groups pivoting about their carbon atoms. Final Fourier syntheses show no significant residual electron density, and there were no abnormal discrepancies between observed and calculated structure factors.

Acknowledgements. Financial support (to L. E.) from the Swedish Natural Science Research Council and the Knut and Alice Wallenberg Foundation is gratefully acknowledged.

\section{References}

1. Butts, C. P., Eberson, L., Fulton, K. L., Hartshorn, M. P. and Robinson, W. T. Aust. J. Chem. 49 (1996) 469.

2. Eberson, L., Hartshorn, M. P. and Radner, F. Acta Chem. Scand. 48 (1994) 937; and references cited therein.

3. Masnovi, J. M., Sankararaman, S. and Kochi, J. K. J. Am. Chem. Soc. 111 (1989) 2262.

4. Eberson, L. and Hartshorn, M. P. J. Chem. Soc., Chem. Commun. (1992) 1564; Eberson, L., Calvert, J. L., Hartshorn, M. P. and Robinson, W. T. Acta Chem. Scand. 48 (1994) 347.

5. Butts, C. P., Eberson, L., Hartshorn, M. P., Robinson, W. T., Timmerman-Vaughan, D. J. and Young, D. A. W. Acta Chem. Scand. 50 (1996) 29.

6. Butts, C. P., Eberson, L., Fulton, K. L., Hartshorn, M. P., Jamieson, G. B. and Robinson, W. T. Acta Chem. Scand. 50 (1996) 735. Butts, C. P., Eberson, L., Foulds, G. J., Fulton, K. L., Hartshorn, M. P. and Robinson, W. T. Acta Chem. Scand. 49 (1995) 76.

7. Calvert, J. L., Eberson, L., Hartshorn, M. P., Maclagan, R. G. A. R. and Robinson, W. T. Aust. J. Chem. 47 (1994) 1211.
8. Eberson, L., Hartshorn, M. P. and TimmermanVaughan, D. J. Acta Chem. Scand. 50 (1996) In press.

9. Bellamy, L. J. Spectrochim. Acta 13 (1958) 60.

10. Bosch, E. and Kochi, J. K. J. Org. Chem. 59 (1994) 3314.

11. Eberson, L., Hartshorn, M. P., Radner, F. and Svensson, J. O. J. Chem. Soc., Perkin Trans. 2 (1994) 1719.

12. Eberson, L., Radner, F. and Lindgren, M. Acta Chem. Scand. 47 (1993) 835; Fritz, H. P. and Artes, R. O. Electrochim. Acta 26 (1981) 417.

13. Eberson, L., Persson, O., Radner, F. and Hartshorn, M. Res. Chem. Intermediat. 22 (1996) 799.

14. Hartshorn, M. P., Readman, J. M., Robinson, W. T. and Vaughan, J. Aust. J. Chem. 38 (1985) 587.

15. Eberson, L., Hartshorn, M. P. and Radner, F. J. Chem. Soc., Perkin Trans. 2 (1992) 1799.

16. (a) Eberson, L., Hartshorn, M. P. and Persson, O. Angew. Chem. Int. Ed. Engl. 34 (1995) 2268. (b) Eberson, L., Hartshorn, M. P. and Persson, O. J. Chem. Soc., Chem. Commun. (1995) 1131. (c) Eberson, L., Hartshorn, M. P. and Persson, O. J. Chem. Soc., Perkin Trans. 2 (1995) 1735. (d) Eberson, L., Hartshorn, M. P. and Persson, O. Acta Chem. Scand. 49 (1995) 640. (e) Eberson, L., Hartshorn, M. P. and Persson, O. J. Chem. Soc., Perkin Trans. 2 (1996) 141. (f) Eberson, L. and Hartshorn, M. P J. Chem. Soc., Perkin Trans. 2 (1996) 151. (g) Eberson, L. Unpublished results.

17. Dessau, R. M., Shih, S. and Heiba, E. I. J. Am. Chem. Soc. 92 (1970) 412

18. Lau, W., Huffmann, J. C. and Kochi, J. K. J. Am. Chem. Soc. 104 (1982) 5515; Lau, W. and Kochi, J. K. J. Org. Chem. 51 (1986) 1801 .

19. Elson, I. H. and Kochi, J. K. J. Am. Chem. Soc. 95 (1973) 5060; Lau, W. and Kochi, J. K. J. Am. Chem. Soc. 106 (1984) 7100.

20. Nyberg, K. and Wistrand, L. -G. Chem. Scr. 5 (1974) 234.

21. Eberson, L., Hartshorn, M. P., Persson, O. and Svensson, J.-O. J. Chem. Soc., Perkin Trans. 2 (1995) 1253.

22. Taylor, E. C. and Danforth, R. H. J. Org. Chem. 38 (1973) 2088.

23. Doba, T., Ichikawa, T. and Yoshida, H. Bull. Chem. Soc. Jpn. 50 (1977) 3124.

24. Tschinkel, J. G. Ind. Eng. Chem. 48 (1965) 732.

25. Fischer, A. and Leonard, D. R. A. Can. J. Chem. 54 (1976) 1795.

26. Gronchi, G. and Tordo, P. Res. Chem. Intermediat. 19 (1993) 733.

27. Sheldrick, G. M., J. Appl. Crystallogr. (1996) In preparation.

Received February 9, 1996. 